\title{
Interannual Variability of Equatorial Eastern Indian Ocean Upwelling: Local versus Remote Forcing*
}

\author{
GENGXIN CHEN \\ State Key Laboratory of Tropical Oceanography, South China Sea Institute of Oceanology, Chinese Academy of \\ Sciences, Guangzhou, China, and Department of Atmospheric and Oceanic Sciences, University of Colorado, \\ Boulder, Boulder, Colorado \\ WEIQING HAN AND YUANLONG LI \\ Department of Atmospheric and Oceanic Sciences, University of Colorado, Boulder, Boulder, Colorado \\ DONGXIAO WANG \\ State Key Laboratory of Tropical Oceanography, South China Sea Institute of Oceanology, Chinese Academy of \\ Sciences, Guangzhou, China
}

(Manuscript received 6 July 2015, in final form 13 December 2015)

\begin{abstract}
The equatorial eastern Indian Ocean (EIO) upwelling occurs in the Indian Ocean warm pool, differing from the equatorial Pacific and Atlantic upwelling that occurs in the cold tongue. By analyzing observations and performing ocean model experiments, this paper quantifies the remote versus local forcing in causing interannual variability of the equatorial EIO upwelling from 2001 to 2011 and elucidates the associated processes. For all seasons, interannual variability of thermocline depth in the EIO, as an indicator of upwelling, is dominated by remote forcing from equatorial Indian Ocean winds, which drive Kelvin waves that propagate along the equator and subsequently along the Sumatra-Java coasts. Upwelling has prominent signatures in sea surface temperature (SST) and chlorophyll- $a$ concentration but only in boreal summer-fall (May-October). Local forcing plays a larger role than remote forcing in producing interannual SST anomaly (SSTA). During boreal summer-fall, when the mean thermocline is relatively shallow, SSTA is primarily driven by the upwelling process, with comparable contributions from remote and local forcing effects. In contrast, during boreal winterspring (November-April), when the mean thermocline is relatively deep, SSTA is controlled by surface heat flux and decoupled from thermocline variability. Advection affects interannual SSTA in all cases. The remote and local winds that drive the interannual variability of the equatorial EIO upwelling are closely associated with Indian Ocean dipole events and to a lesser degree with El Niño-Southern Oscillation.
\end{abstract}

\section{Introduction}

The Indo-Pacific warm pool is an important feature of the climate system and is capable of influencing global climate (Sardeshmukh and Hoskins 1988; Webster and

\footnotetext{
* Supplemental information related to this paper is available at the Journals Online website: http://dx.doi.org/10.1175/JPO-D-15-0117.s1.

Corresponding author address: Gengxin Chen, State Key Laboratory of Tropical Oceanography, South China Sea Institute of Oceanology, Chinese Academy of Sciences, 164 West Xingang Road, Guangzhou 510301, China. E-mail: chengengxin@scsio.ac.cn
}

Lukas 1992; Kim et al. 2012). As part of the Indo-Pacific warm pool, the tropical equatorial eastern Indian Ocean (EIO) region possesses high sea surface temperature (SST) and a deep thermocline. Seasonal upwelling, however, occurs in the EIO warm pool, particularly along the coasts of Java and Sumatra and extends toward the equator (Fig. 1; Susanto et al. 2001). During 1994 and 1997, stronger upwelling events occurred and a cold wedge formed in the EIO with a SST anomaly (SSTA) of lower than $-1^{\circ} \mathrm{C}$ extending to the west of $90^{\circ} \mathrm{E}$ (Du et al. 2008). These results indicate that upwelling can significantly affect the EIO warm pool SST and therefore might be important for influencing regional and global climate. In addition, the equatorial 

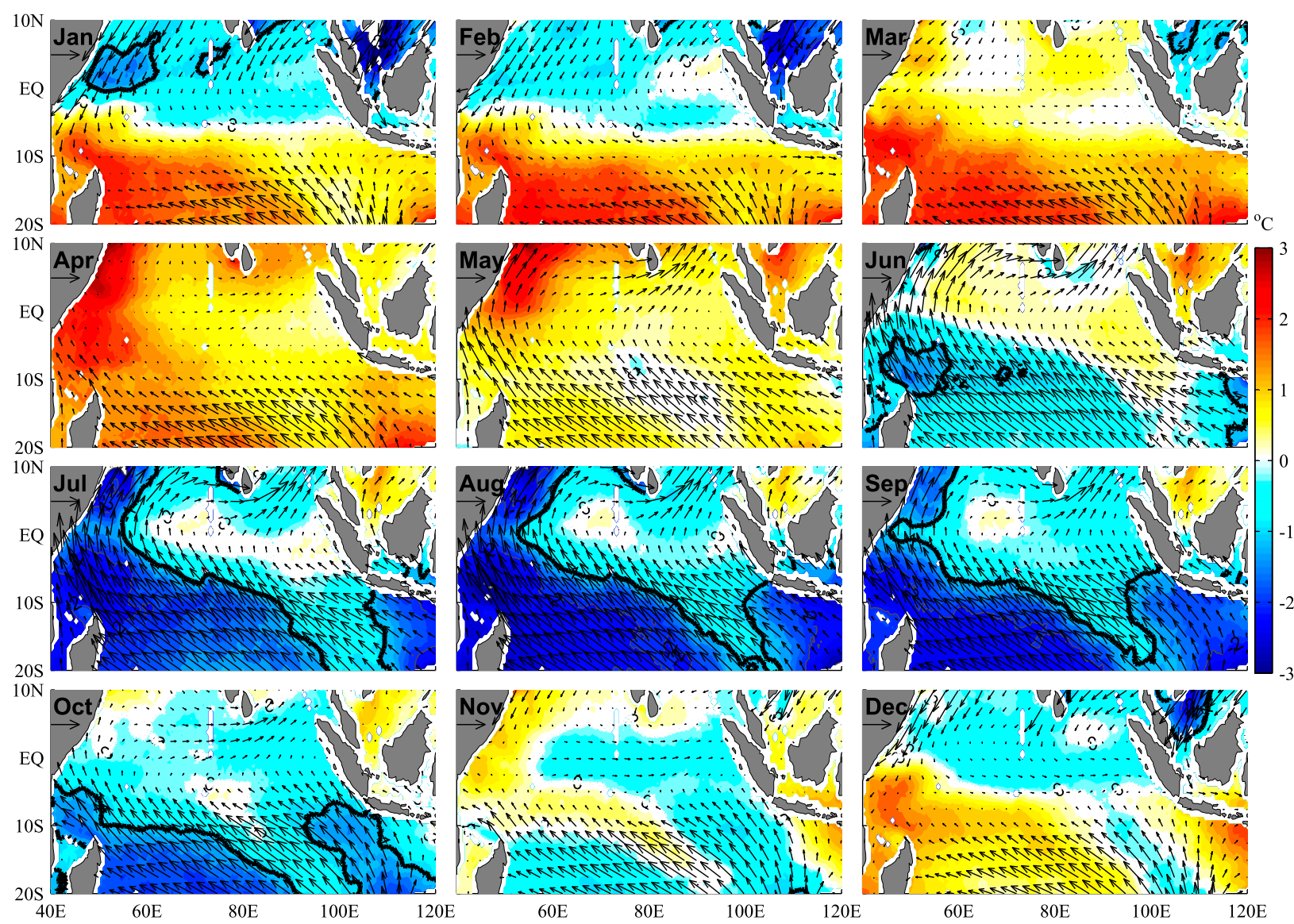

FIG. 1. Monthly climatology of CCMP surface wind stress (vectors; $\mathrm{N} \mathrm{m}^{-2}$ ) and SSTA (color shading; ${ }^{\circ} \mathrm{C}$ ) from TMISST during 2001-2011 The thick black lines denote $-1^{\circ} \mathrm{C}$ SSTA contour. The scale in the upper-left corner of each panel represents $0.15 \mathrm{~N} \mathrm{~m}^{-2}$ wind stress.

EIO upwelling corresponds to increased chlorophyll- $a$ (Chl- $a$ ) concentration and phytoplankton bloom and thus is important for the costal ecosystem and fisheries (e.g., Susanto and Marra 2005; Iskandar et al. 2009; Baumgart et al. 2010). It is also verified that the equatorial EIO upwelling entrains radiocarbon-depleted water from the subsurface, which dilutes the effect of the uptake of bomb-produced radiocarbon by the surface ocean (Grumet et al. 2004).

Driven by the southeast monsoon, seasonal upwelling of the EIO tends to occur from June to October and is eventually terminated by the reversal of winds associated with the onset of the northwest monsoon (Fig. 1) and the arrival of Indian Ocean equatorial Kelvin wave (Clarke and Liu 1993; Susanto et al. 2001). This seasonal upwelling exhibits strong interannual variability, which is most pertinent to the occurrence of Indian Ocean dipole (IOD) events, such as the strong 1994 and 1997 IOD events (Saji et al. 1999; Webster et al. 1999; Murtugudde et al. 2000). The IOD is suggested to be a coupled ocean-atmosphere mode over the Indian Ocean, but it is also significantly correlated with El Niño-Southern Oscillation (ENSO;
Saji et al. 1999; Murtugudde et al. 2000). Susanto et al. (2001) argued that significant interannual variability of the Java-Sumatra upwelling is linked to ENSO through both the Indonesian Throughflow (ITF) and anomalous easterly wind via the atmospheric bridge. Du et al. (2008) pointed out that during the positive IOD years, the depth of the thermocline has a prominent influence on the generation and maintenance of SSTA. During normal years, cooling by upwelling and entrainment is largely counterbalanced by the warming induced by horizontal advection. In addition to local wind forcing, propagation of equatorial and coastal Kelvin waves can also affect upwelling in the equatorial EIO. By separately suppressing interannual wind forcing east and west of $90^{\circ} \mathrm{E}$, Murtugudde et al. (2000) concluded that the SSTA off Sumatra for the 1997/ 98 IOD event was forced roughly equally by local alongshore winds and remote equatorial winds.

Different from the upwelling of the eastern equatorial Pacific and Atlantic cold tongue, where the mean thermocline is shallow and variability of thermocline depth is highly correlated with SSTA, the equatorial EIO upwelling occurs in the warm pool where the mean 
thermocline is usually deep. Consequently, the thermocline depth anomaly presents weak correlation with SSTA on interannual time scales in most of the region of the EIO (Xie et al. 2002). The equatorial EIO upwelling is significantly affected by massive equatorial waves (e.g., Murtugudde et al. 2000; Chen et al. 2015b), and the reflected Rossby waves spread the upwelling signals from the coasts into the interior (see section $2 b$ ). As a result, the equatorial EIO upwelling considerably alters the warm pool SST (e.g., Du et al. 2008; Fig. 2b) and thus potentially affects regional and global climate. Because of its uniqueness, the equatorial EIO upwelling has been identified as one of the research priorities by the CLIVAR Indian Ocean Panel of the World Climate Research Program, and the equatorial EIO upwelling research initiative has been proposed to understand its dynamics and ecosystem impacts [see CLIVAR/Intergovernmental Oceanographic Commission Global Ocean Observing System (IOC-GOOS) Indian Ocean Region Panel Achievements and Future Plans at http://www.clivar. org/clivar-panels/indian].

The goal of this research is to assess the effects of remote and local forcing over the Indian Ocean in promoting equatorial EIO upwelling on interannual time scales, with a specific focus on examining the interannual variability of thermocline depth, sea surface height (SSH), SST, and Chl- $a$ concentration from 2001 to 2011, a period when high-quality satellite data are available to force the ocean model. Even though Murtugudde et al. (2000) assessed the remote versus local impacts on SSTA for the 1997 IOD event, systematic studies that quantitatively examine the effects of remote and local forcing on the equatorial EIO upwelling system have not yet been conducted. Furthermore, while both ENSO and IOD were thought to affect the equatorial EIO upwelling (e.g., Susanto et al. 2001; Murtugudde et al. 2000), just which one is more significant remains unclear. In this study, we also present evidence that the winds that drive interannual variability of the equatorial EIO upwelling is closely associated with IOD. The rest of the paper is organized as follows: Section 2 describes data, model, and experiments. Section 3 verifies the HYCOM performance and investigates remote versus local wind forcing over the Indian Ocean in generating equatorial EIO upwelling. Section 4 provides a summary and discussion.

\section{Data, ocean model, and experiments}

\section{a. Data}

The Tropical Rainfall Measuring Mission (TRMM) Microwave Imager SST (TMISST) products are available from December 1997 with a horizontal resolution of $0.25^{\circ} \times 0.25^{\circ}$. Daily, 3-day, weekly, and monthly products are provided (Wentz et al. 2000). The SST data from January 2001 to November 2011, our period of interest when all satellite data are available to force the ocean model (section 2b), are analyzed.

The weekly SSH anomalies (SSHAs) available since October 1992, distributed by the Archiving, Validation, and Interpretation of Satellite Oceanographic data (AVISO) (Le Traon et al. 1998; Ducet et al. 2000; Rio et al. 2011) for 2001-11, are used to understand interannual variability of SSH in the EIO. The European Centre for Medium-Range Weather Forecasting (ECMWF) Ocean Reanalysis System 4 (ORAS4; Balmaseda et al. 2013) temperature data, available since 1958 with a horizontal resolution of $1^{\circ} \times 1^{\circ}$ and 42 vertical levels, are used to examine the thermocline depth, which is represented by the depth of $23^{\circ} \mathrm{C}$ isotherm (D23). Here, we choose to use D23 instead of D20 because the vertical temperature gradients along the eastern Indian Ocean equator, along the Sumatra and Java coasts, and averaged in the study region of the EIO all obtain their maximum values near D23 (figures not shown). We have also analyzed D20 and obtained similar results.

The cross-calibrated multiplatform (CCMP) satellite ocean surface wind vectors are available during January 1988-December 2011 (Atlas et al. 2008). Monthly Seaviewing Wide Field-of-view Sensor (SeaWiFS) Chl- $a$ concentrations during 2001-10, the maximum overlap with our period of interest, derived from the NASA/ Goddard Earth Sciences (GES)/Distributed Active Archive Center (DAAC; Aiken et al. 1995) are used to investigate the Chl- $a$ variations in the EIO. The data are mapped to a spatial resolution of nearly $9 \mathrm{~km}$. The Niño3 index, which is a time series of area-averaged SST from $5^{\circ} \mathrm{S}$ to $5^{\circ} \mathrm{N}$ and $150^{\circ}$ to $90^{\circ} \mathrm{W}$, is used to show ENSO events. As a comparison, the Niño-3.4 index, which is a time series of area-averaged SST from $5^{\circ} \mathrm{S}$ to $5^{\circ} \mathrm{N}$ and $170^{\circ}$ to $120^{\circ} \mathrm{W}$, is also used for our analysis. Both are downloaded online (from http://www.esrl.noaa.gov/psd/ gcos_wgsp/Timeseries/). The dipole mode index (DMI), which is defined as the SSTA difference between the western node $\left(10^{\circ} \mathrm{S}-10^{\circ} \mathrm{N}, 50^{\circ}-70^{\circ} \mathrm{E}\right)$ and eastern node $\left(10^{\circ} \mathrm{S}-0^{\circ}, 90^{\circ}-110^{\circ} \mathrm{E}\right)$ regions (Saji et al. 1999$)$, is used to identify IOD events (and is downloaded from http:// stateoftheocean.osmc.noaa.gov/sur/ind/dmi.php). The SST, SSHA, D23, and CCMP wind for the period of January 2001 to November 2011 and Chl- $a$ from January 2001 to December 2010 are used to calculate their climatologies and interannual anomalies.

\section{b. Ocean model and experiments}

The ocean general circulation model used in this study is a recent version (2.2.18) of the Hybrid Coordinate 

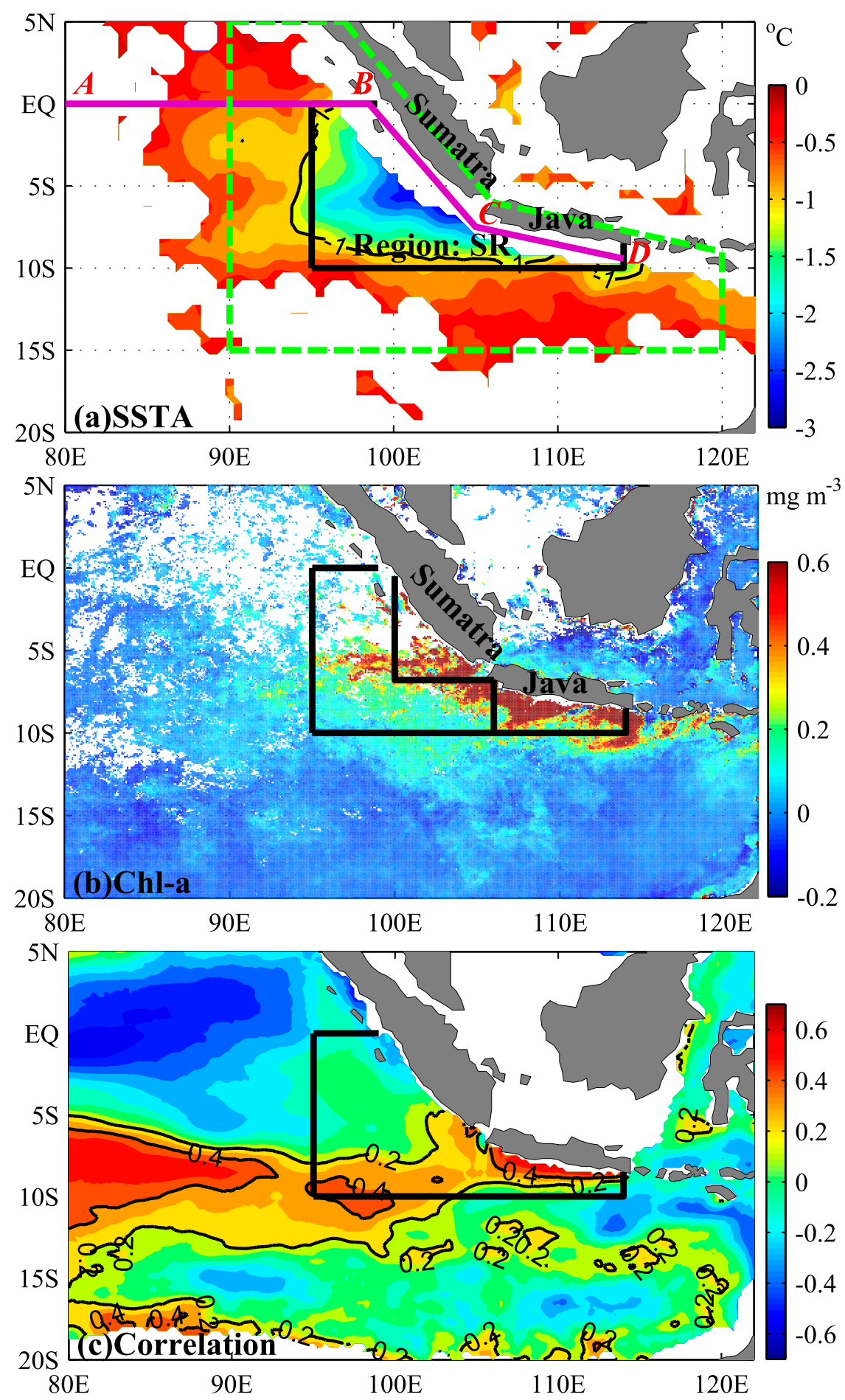

FIG. 2. (a) SSTA from TMISST in September 2006. Only the negative SSTA values are shown. The black box shows the SR. The regions between SR and dashed green lines mark the transient regions, where the real forcing gradually changes to monthly climatological forcing in the SR. The purple line is used to show propagation of Kelvin waves along the equator and coasts of Sumatra and Java, with letters A-D showing the start, turn, and end positions of the purple line. Their longitudes are $80^{\circ}, 98.5^{\circ}, 105^{\circ}$, and $114^{\circ} \mathrm{E}$, respectively. (b) Chl- $a$ anomaly in September 2006. White areas are due to missing data. (c) Correlation between interannual SSTA and D23A for all months from 2001 to 2011. 
Ocean Model (HYCOM; e.g., Bleck 2002; Wallcraft et al. 2009) configured to the Indian Ocean basin $\left(50^{\circ} \mathrm{S}_{-}\right.$ $30^{\circ} \mathrm{N}, 30^{\circ}-122.5^{\circ} \mathrm{E}$ ) with a horizontal resolution of $0.25^{\circ} \times 0.25^{\circ}$ and 26 vertical layers. The surface forcing fields include daily $0.25^{\circ} \times 0.25^{\circ}$ CCMP surface winds available from July 1987 to December 2011, 2-m air temperature and humidity from the ECMWF interim reanalysis (ERA-Interim) products (Dee et al. 2011) available since 1979, surface shortwave and longwave radiation from Clouds and the Earth's Radiant Energy System (CERES; Wielicki et al. 1996; Loeb et al. 2001) available since 2000 , and precipitation from the $0.25^{\circ} \times$ $0.25^{\circ}$ TRMM Multisatellite Precipitation Analysis (TMPA) level 3B42 product (Kummerow et al. 1998) available for 1998-2011. Surface latent and sensible heat fluxes are calculated from wind speed, air temperature, specific humidity, and model SST using the Coupled Ocean-Atmosphere Response Experiment (COARE 3.0) algorithm (Kara et al. 2005). More information about the model configuration and forcing fields can be found in Li et al. (2014). The diffusion and mixing parameters are detailed in $\mathrm{Li}$ et al. (2013). Earlier versions of HYCOM have been successfully used to understand wave dynamics in the equatorial Indian (e.g., Han et al. 2011) and Atlantic Oceans (e.g., Han et al. 2008).

Taking the World Ocean Atlas 2009 (WOA09) annual climatology of temperature and salinity as the initial condition, the model is spun up from a state of rest for $30 \mathrm{yr}$ using the monthly climatological forcing fields (see section 2a). Restarting from the spunup solution, HYCOM is integrated forward from 1 March 2000 to 30 November 2011 with the daily forcing fields described above. This experiment is referred to as the main run (MR). To exclude the transient effect from the spinup, the model output in 2000 is discarded, and we analyze the 3-day-averaged model outputs from 2001 to 2011.

While the EIO region in HYCOM experiments spans $90^{\circ}-120^{\circ} \mathrm{E}$ zonally and $15^{\circ} \mathrm{S}-5^{\circ} \mathrm{N}$ meridionally (dashed green line enclosed area of Fig. 2a), here we choose a subarea of $10^{\circ} \mathrm{S}-0^{\circ}, 95^{\circ}-114^{\circ} \mathrm{E}$ as our study region (SR; black box in Fig. 2a) to quantify the upwelling in the EIO. The SR is very similar to the eastern antinode region of the IOD $\left(10^{\circ} \mathrm{S}-0^{\circ}, 90^{\circ}-110^{\circ} \mathrm{E}\right.$; see Saji et al. 1999$)$, and it is chosen to cover the obvious negative SSTA (Fig. 2a) and high Chl- $a$ concentration (Fig. 2b) regions in the fall of 2006, the strongest equatorial EIO upwelling event that occurred during the 2001-11 period. As the upwelling is located near the equator, strong equatorial Kelvin wave signals can propagate to the EIO boundary and subsequently reflect back into the ocean interior as Rossby waves in the SR (Figs. S1 and S2 in supplemental information), which spread the upwelling signals from the coasts into the SR interior. Similarly, coastal upwelling driven by interannual variability of local winds near Sumatra and Java also radiate westward as Rossby waves. This is because the critical latitudes (McCreary et al. 1986; Girishkumar et al. 2013) for Rossby waves on interannual time scales are much higher than $10^{\circ} \mathrm{S}$ for the first four baroclinic modes, and thus Rossby waves for the gravest modes exist in the SR.

The critical latitude is defined as $\tan \left(\theta_{c}\right)=c /(2 \omega R)$, where $\theta_{c}$ is the critical latitude, $c$ is baroclinic mode speed, $R$ is Earth's radius, $\omega$ is the frequency with $\omega=(2 \pi) / T$, and $T$ is the period. Rossby waves propagate westward in regions equatorward of the critical latitude, but they are damped quickly in regions poleward of the critical latitude. Based on ORAS4, the baroclinic mode speeds for the first four baroclinic modes in the SR are $2.73,1.37,0.91$, and $0.68 \mathrm{~m} \mathrm{~s}^{-1}$, respectively. Their corresponding critical latitudes for Rossby waves with an annual period ( $T=360$ days) are $46.8^{\circ}, 28.0^{\circ}, 19.6^{\circ}$, and $12.0^{\circ} \mathrm{S}$. For interannual variability $(T>360$ days $)$, their critical latitudes are even higher, which is much higher than the SR latitudes.

To assess the relative contributions of local and remote forcing to upwelling in the EIO, an additional experiment (EXP) is performed, in which intraseasonal, interannual, and longer time scale variability of forcingincluding shortwave radiation, longwave radiation, wind stress, wind speed, precipitation, air temperature, and specific humidity-are removed and only their monthly climatologies are retained in the SR. Beyond the EIO region (green dashed line in Fig. 2a), forcing fields in EXP is the same as in the MR. The area between the SR and the green dashed boundary lines is the transition area, where monthly climatological forcing in the SR gradually transits to the realistic daily forcing. Therefore, interannual upwelling and SST variations in the SR of EXP are mainly caused by remote forcing effect, which affects the EIO primarily through propagation of equatorial waves and advection. The solution difference MR - EXP measures the effect of local forcing (e.g., shortwave and longwave radiation, turbulent heat flux, and upwelling driven by winds local to the SR). The 3-day-averaged model outputs from both experiments are averaged into monthly data. To highlight interannual variations, we further remove the monthly climatology of the 2001-11 period to obtain the interannual anomalies.

\section{Results}

\section{a. Model/data comparison}

The modeled SSTA (at $1.3 \mathrm{~m}$ ) in the EIO shows consistent variability with TMISSTA (Fig. 3a), and their 

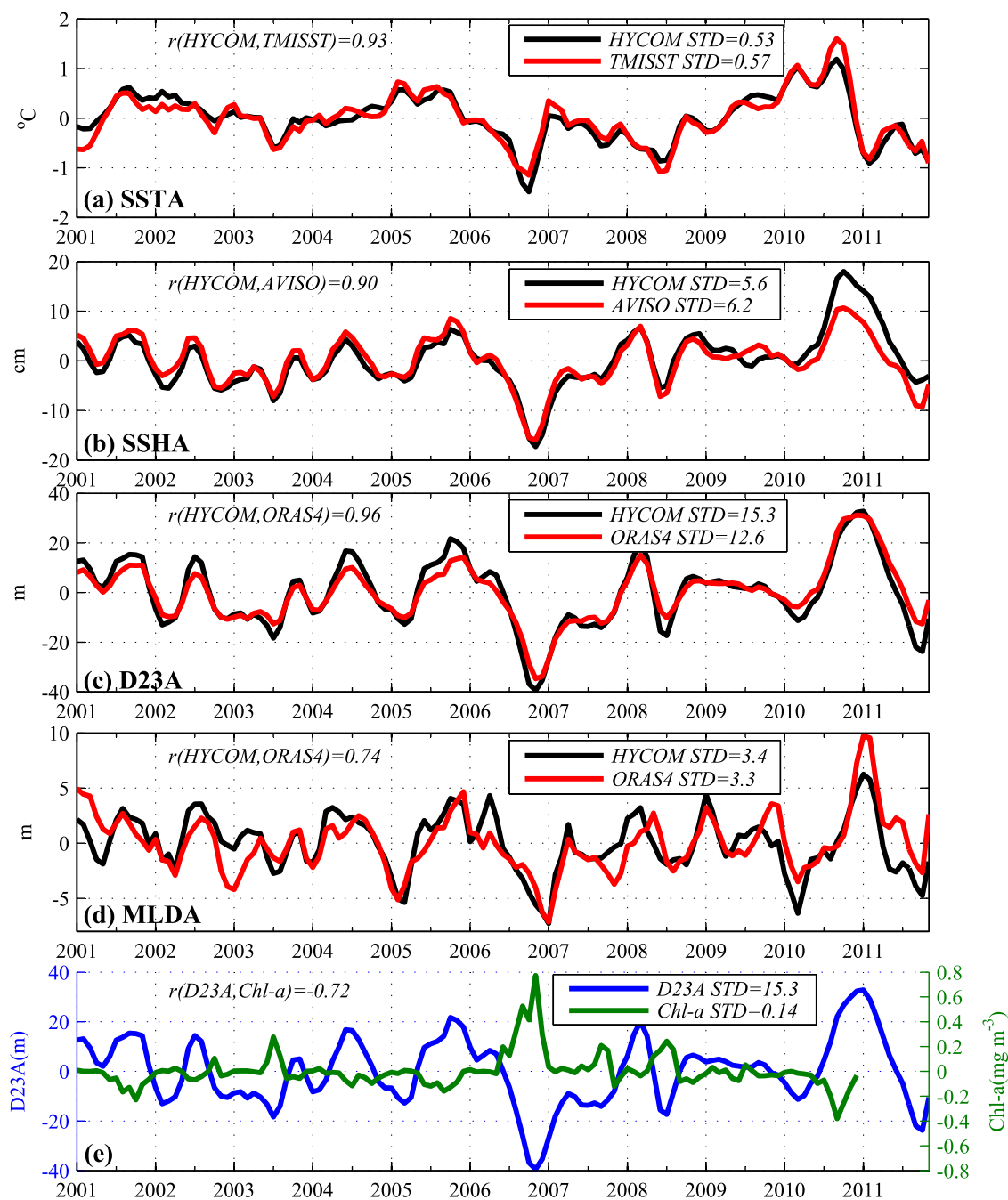

FIG. 3. Interannual variability averaged in the SR for (a) SSTA from HYCOM and TMISST; (b) SSHA from AVISO and HYCOM; (c) D23A from HYCOM and ORAS4; (d) MLD anomaly from HYCOM and ORAS4; and (e) D23A from HYCOM and Chl- $a$ concentration anomaly from SeaWiFS.

correlation coefficient is 0.93 (above the $95 \%$ confidence level). Note that SST in HYCOM is measured at 1.3-m depth, whereas the satellite-based TMISST is the skin-layer temperature. This difference contributes to the modeled/observed SSTA discrepancy (black and red curves of Fig. 3a).

The SSHA and D23 anomaly (D23A) are examined to further verify HYCOM performance in simulating the interannual variability of equatorial EIO upwelling. HYCOM SSHA agrees well with the AVISO data (Fig. 3b), with a correlation coefficient of 0.90 and observed/simulated standard deviations (STDs) of 6.2/ $5.6 \mathrm{~cm}$. HYCOM can also realistically simulate the interannual variability of D23, with a correlation coefficient of 0.96 between HYCOM and ORAS4 data and
STDs of 15.3 and $12.6 \mathrm{~m}$ for HYCOM and ORAS4, respectively (Fig. 3c). Interannual variability of the mixed layer depth (MLD) from HYCOM also agrees reasonably well with that from ORAS4 (Fig. 3d); their correlation coefficient is 0.74 , and their STDs are 3.3 and $3.4 \mathrm{~m}$, respectively. Here, the MLD is defined as the depth at which the potential density difference from the $5-\mathrm{m}$ value is equal to the density change resulting from a $0.5^{\circ} \mathrm{C}$ temperature decrease.

The D23A, a representative index for interannual variability of equatorial EIO upwelling, is highly correlated with Chl- $a$ anomaly (Fig. 3e), with their correlation coefficient being -0.72 . The correlations between the observed Chl- $a$ concentration anomaly and SSTA from HYCOM (TMISST) are $-0.73(-0.68)$. Different 

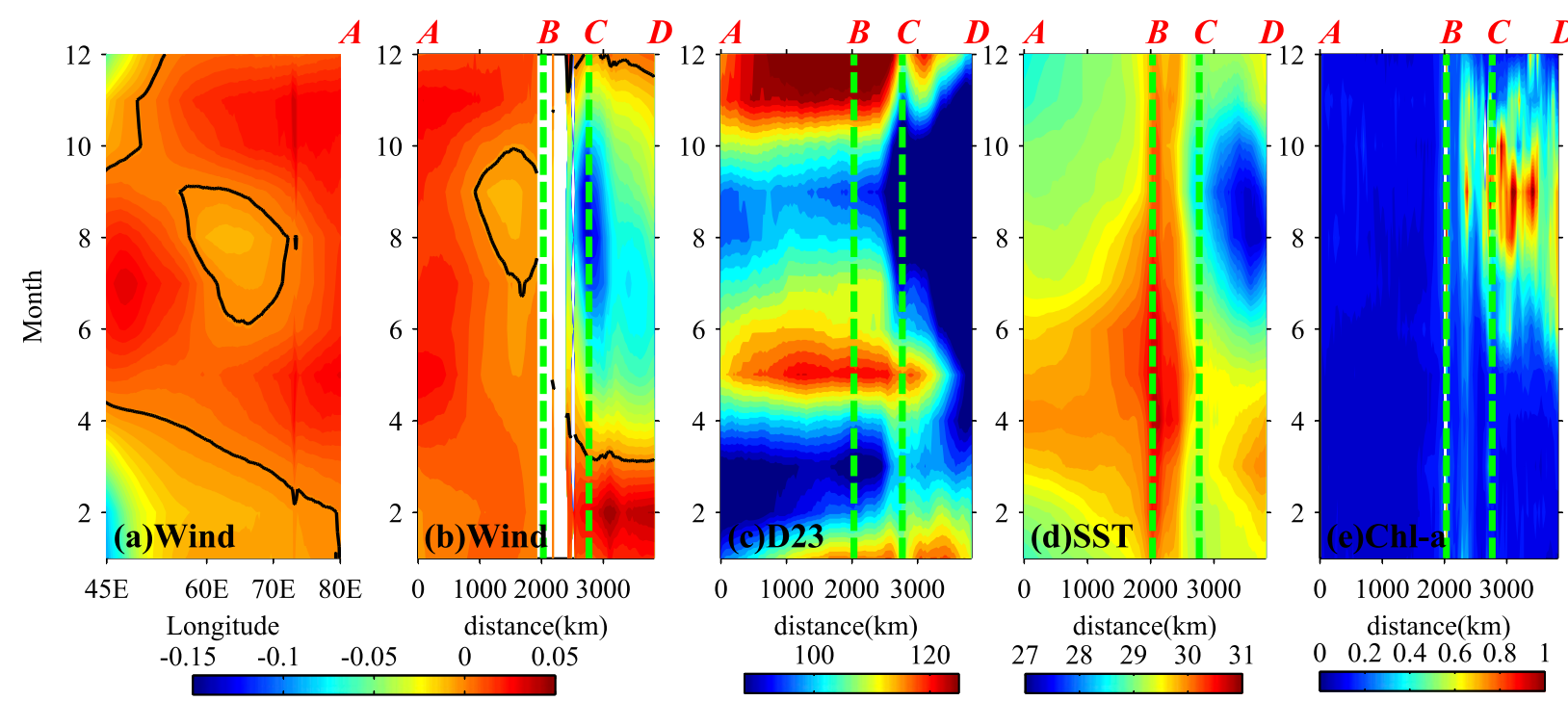

FIG. 4. (a) Time-longitude plots of monthly climatological CCMP zonal wind stress $\left(\mathrm{N} \mathrm{m}^{-2}\right)$ along the equator from $45^{\circ}$ to $80^{\circ} \mathrm{E}$ for the 2001-11 period. (b) CCMP wind stress $\left(\mathrm{N} \mathrm{m}^{-2}\right)$, (c) HYCOM D23 (m), (d) HYCOM SST $\left({ }^{\circ} \mathrm{C}\right)$, and (e) Chl- $a\left(\mathrm{mg} \mathrm{m}^{-3}\right)$ from SeaWiFS. (b)-(e) are the time-distance plots along the blue line in Fig. 2a from $\mathrm{A}\left(80^{\circ} \mathrm{E}\right)$ to $\mathrm{D}$, with locations of $\mathrm{A}, \mathrm{B}, \mathrm{C}$, and $\mathrm{D}$ being marked on the top of each panel. Black lines in (a) and (b) represent zero value of wind stress, and positive values in (b) between A-B (B-D) represent eastward (southeastward) wind stress along the equator (coast). White areas in (b) are due to missing data.

from the situation in the eastern equatorial Pacific Ocean (e.g., Zelle et al. 2004), interannual D23A has no significant correlation with interannual SSTA in the EIO. Their correlation coefficient is only 0.26 averaged over the SR during 2001-11. By calculating correlation coefficients between SSTA and D23A in each model grid, however, larger correlation coefficients $(\sim 0.4)$ are found near the Java coast (Fig. 2c). This result agrees with Xie et al. (2002), who focused on examining interannual SST and thermocline variability in the southwest tropical Indian Ocean thermocline ridge region. For further validations of HYCOM, please read Li et al. $(2014,2015)$ and Chen et al. (2015a). The good model/data agreements suggest that HYCOM is able to capture the fundamental processes governing the equatorial EIO upwelling and thus is suitable for our investigation.

\section{b. Seasonal upwelling}

The southeast monsoonal winds during June-October favor the development of upwelling near the coasts of Sumatra and Java. They generate cold SST, low SSH, and high Chl- $a$ in the EIO (Fig. 1). Because of its adjacency to the equator, the equatorial EIO upwelling is inevitably affected by the equatorial waves. Equatorial zonal winds exhibit strong semiannual variability, with equatorial westerlies prevailing during April-June and October-December and weak westerlies (or easterlies) during January-March and July-September (Figs. 1, $4 a, b$ between A and B). Correspondingly, equatorial upwelling, which is represented by a shoaling thermocline, occurs twice a year, with evident eastwardpropagating shallow D23 signals during January-March and July-September (Fig. 4c). Upon reaching the eastern boundary, the shallow D23 signals continue to propagate southeastward along the coasts of Sumatra and Java as coastally trapped Kelvin waves (Fig. 4c, B-D).

During boreal winter-early spring, equatorial upwelling is primarily forced by the strong easterlies in the western-to-central equatorial basin (Fig. 4a; also see Fig. 9 in Chen et al. 2015a), and the propagation of D23 signals affects the thermocline in the EIO. Hereafter, seasons refer to those of the Northern Hemisphere. The local winds east of $80^{\circ} \mathrm{E}$ and along the Sumatra-Java coasts (from A to D), however, are downwelling favorable (Fig. 4b), which counteract the upwelling effect caused by the equatorial winds west of $80^{\circ} \mathrm{E}$ and result in very weak upwelling in the EIO (Fig. 4c). This weak upwelling does not cause a peak in Chl- $a$ concentration during the winter-early spring season (Fig. 4e). By contrast, the strong upwelling-favorable local alongshore winds during summer-fall (May-October; Figs. 1, 4b) enhance the upwelling generated by the equatorial easterlies (or weakened westerlies) (Fig. 4b; also see Fig. 13 in Chen et al. 2015a) and promote strong equatorial EIO upwelling (Fig. 4c), which is accompanied with cold SST and high Chl- $a$ concentration (Figs. 4d-e). The cold SSTA influences the Indo-Pacific warm pool and thus regional and global climate (Kim et al. 2012). 

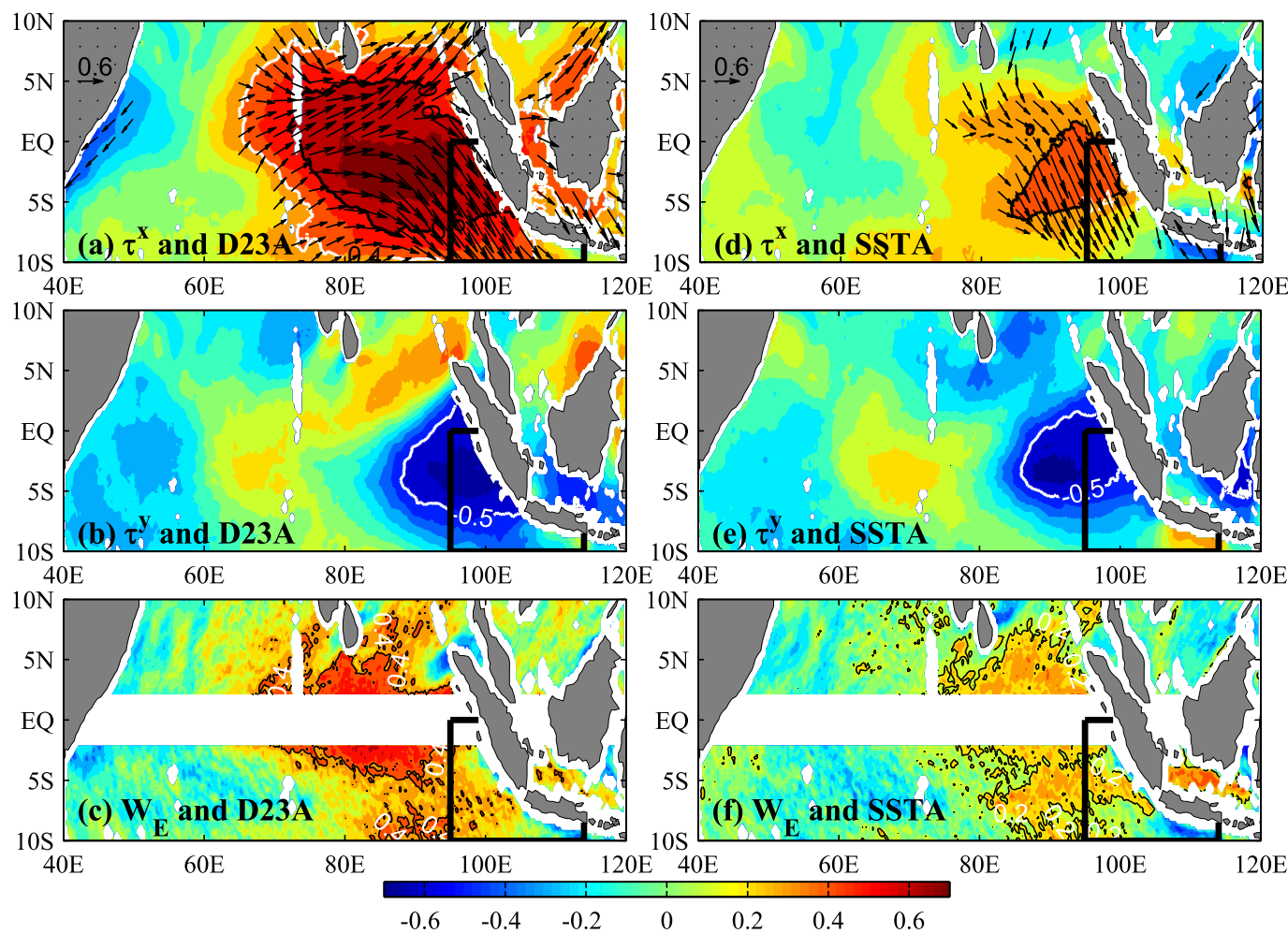

FIG. 5. (a) Correlation coefficients between interannual anomaly of zonal wind stress $\tau^{x}$ at each grid point and D23A averaged in the SR (black box) from HYCOM MR using monthly data from January 2001 to November 2011. (b) As in (a), but for meridional wind stress anomaly $\tau^{y}$ and D23A. (c) As in (a), but for Ekman pumping velocity anomaly $W_{E}$ and D23A. (d) As in (a), but for $\tau^{x}$ and SSTA. (e) As in (a), but for $\tau^{y}$ and SSTA. (f) As in (a), but for $W_{E}$ and SSTA. The thick line contour in (a)-(f) represents 0.6 and $0.4,-0.5,0.4,0.4,-0.5$, and 0.2 contours in each panel, respectively. Regression coefficients of D23A and SSTA onto wind stress anomaly are shown in (a) and (b) by vectors. Only regions with correlation coefficient over 0.3 are plotted.

Different from D23, SST does not show apparent propagation features.

\section{c. Interannual variability}

\section{1) OBSERVATIONAL ANALYSis}

Upwelling over the EIO shows obvious interannual variability (Fig. 3; Susanto et al. 2001; Du et al. 2008). Correlation analysis demonstrates that interannual variability of D23 in the SR is affected by both local and remote wind stress (Figs. 5a,b). The correlation coefficient contour of 0.6 extends to $72^{\circ} \mathrm{E}$ in Fig. 5a (black line contour), suggesting that zonal wind stress in the equatorial Indian Ocean contributes significantly to the EIO D23 variability. This means that the easterly (westerly) wind anomalies along the equator tend to shoal (deepen) D23 over the EIO and thus enhance (weaken) the equatorial EIO upwelling. Although SSTA in the SR is also correlated with equatorial zonal wind stress (Fig. 5d), their correlations are significantly weaker (0.3-0.4), suggesting that remote forcing by the equatorial zonal wind stress may have less impact on the EIO SSTA compared to D23A when all months are considered (Figs. 5a,d). The southerly winds near the Sumatra coast have high negative correlations with both SSTA and D23A (Figs. 5b,e), and regression coefficients for D23A and SSTA regressed onto wind stress (vectors in Figs. 5a,d) suggest the importance of alongshore winds in causing equatorial EIO upwelling. Evidently, remote influence of equatorial winds on D23A and SSTA results primarily from the zonal wind component, with meridional wind effects being largely local to the upwelling region.

In addition to the zonal and meridional wind stress anomalies, the Ekman pumping velocity anomaly, which is associated with wind stress curl and defined as $w_{\mathrm{e}}=$ $\operatorname{curl}(\tau / f) \rho_{0}^{-1}$, is also correlated with D23A and SSTA in the equatorial EIO upwelling region (Figs. $5 \mathrm{c}, \mathrm{f})$. Here, $\rho_{0}$ is the mean density of seawater, $f$ is Coriolis parameter, and $\boldsymbol{\tau}=$ $\left(\tau^{x}, \tau^{y}\right)$ is the wind stress vector with zonal and meridional components. Interestingly, the EIO D23A is significantly correlated with neither $\tau^{x}$ nor $\tau^{y}$ near the Java coast (Figs. 5a,b), and SSTA is correlated negatively with $\tau^{x}$ and positively with $\tau^{y}$. These results indicate that alongshore winds off the Java coast are not the cause for the SSTA averaged in 

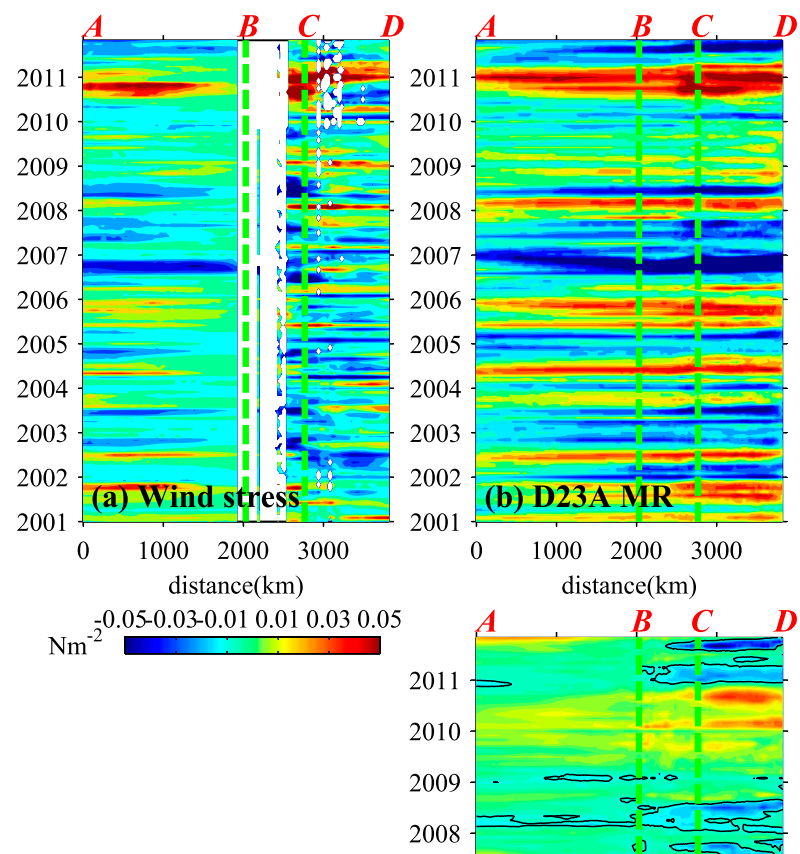

2007

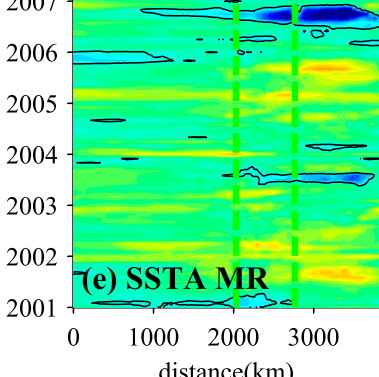

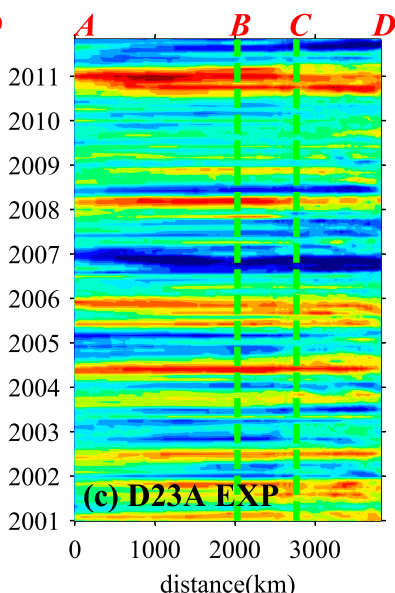
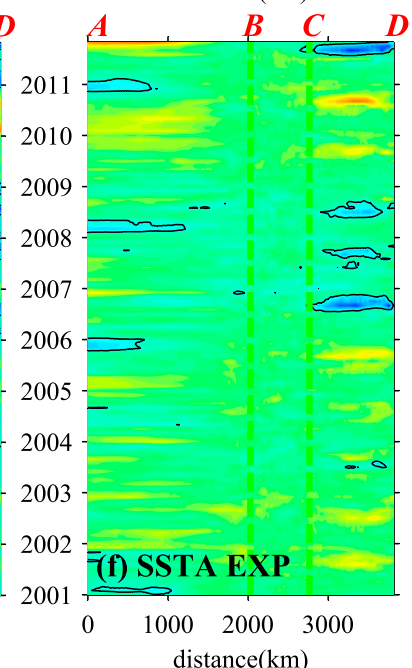
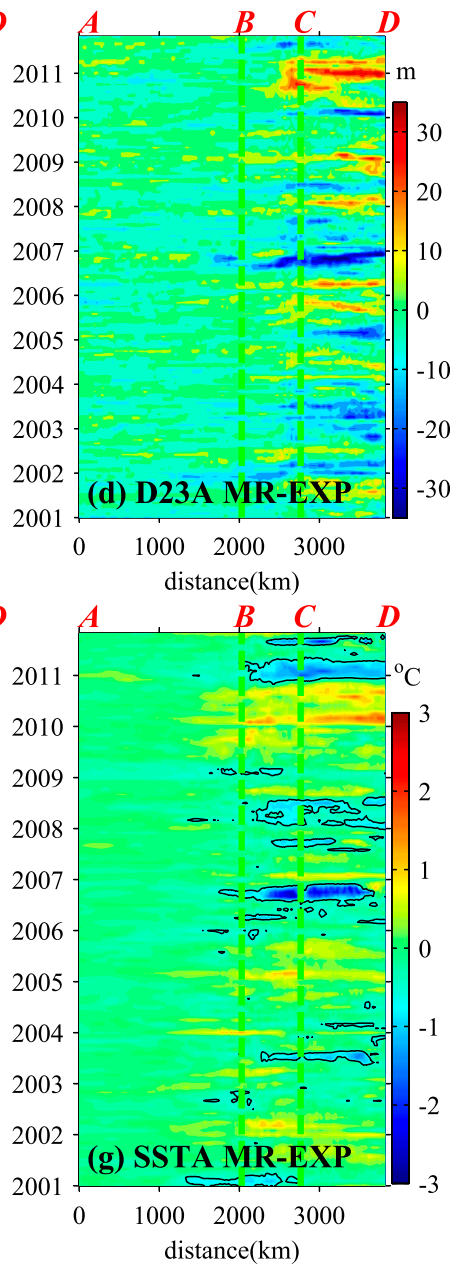

FIG. 6. (a) Time distance plots of interannual variability of wind stress along the blue line in Fig. 2. (b)-(d) As in (a), but for D23A from (b) MR, (c) EXP, and (d) their difference MR - EXP. (e)-(g) As in (b)-(d), but for SSTA from HYCOM. Positive values in (a) between A-B (B-D) represents eastward (southeastward) wind stress along the equator (coast). White areas are due to missing data. Black contours in $(\mathrm{e})-(\mathrm{g})$ represent $-0.5^{\circ} \mathrm{C}$.

the SR, because negative (positive) $\tau^{x}\left(\tau^{y}\right)$ is upwelling favorable and thus should be positively (negatively) correlated with SSTA. The $w_{\mathrm{e}}$ anomaly along the Java and Sumatra coasts, on the other hand, is negatively correlated with both SR D23A and SSTA, with the positive $w_{\mathrm{e}}$ anomaly representing shoaling thermocline and cold SSTA and thus may have contributed to the EIO SSTA and D23A. Away from the coasts, the $w_{\mathrm{e}}$ anomaly becomes positively correlated with D23A and SSTA averaged for the SR (Figs. 5c,f), indicating that the wind stress curl anomaly there acts to damp the D23 and SST variations that are mainly induced by remote forcing from equatorial $\tau^{x}$ and alongshore wind near the Sumatra-Java coasts (Figs. 5a,b and 5d,e).

\section{2) REMOTE VERSUS LOCAL FORCING EFFECTS}

To quantify the remote versus local wind forcing effects, we examine the time-distance plots of interannual D23A and SSTA along the blue line A-D in Fig. 2a from HYCOM MR (complete solution), EXP that measures remote influence, and their difference MR - EXP that estimates the local forcing (section 2b), together with interannual anomaly of surface wind stress (Fig. 6). Obviously, interannual D23A propagates eastward along the equator and then southeastward along the coasts of Sumatra and Java, with large D23A being observed during summer-fall due to the stronger interannual variability of equatorial winds in these seasons (Figs. 6a,b; Schott and McCreary 2001). The D23As in the EIO are predominantly forced remotely by the equatorial winds, with local wind forcing having substantial contributions in some years (e.g., 2006 and 2010). Note that HYCOM EXP can well simulate the mean seasonal cycles of D23 and SST in the SR (Figs. 7a,c), with the difference between MR and EXP being less than $2 \%$. This result indicates that remote 

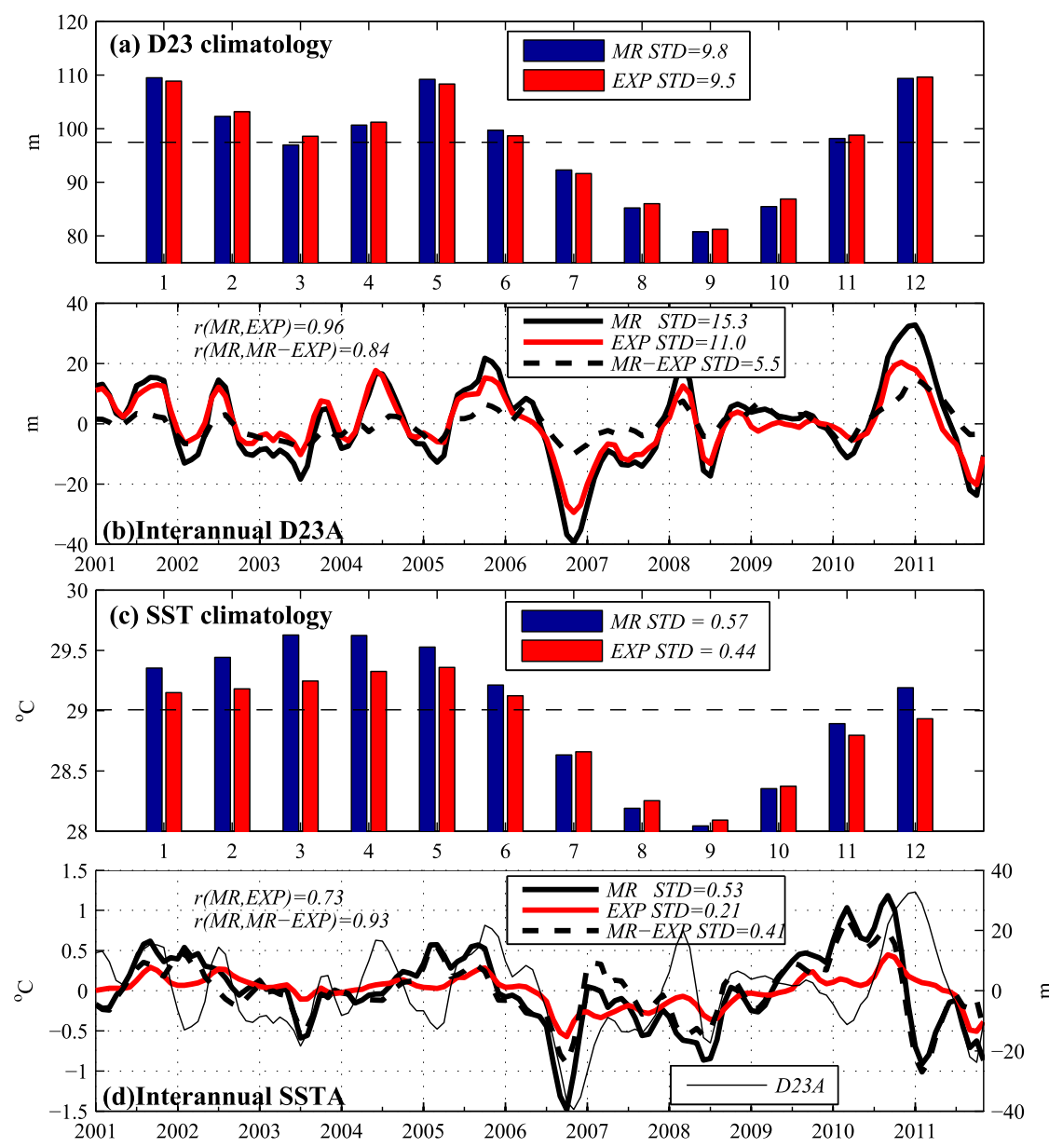

FIG. 7. (a) Monthly climatology and (b) interannual anomaly of D23 from MR and EXP averaged in the EIO SR. (c),(d) As in (a) and (b), but for SST. The MR D23A is repeated by thin solid line in (d). Dashed horizontal lines in (a) and (c) are the mean values of D23 (97.4 m) and SST $\left(29.01^{\circ} \mathrm{C}\right)$ from January 2001 to November 2011.

and local forcings induce interannual D23A and SSTA primarily through interannual variability of the forcing fields, rather than through changing the climatologicalmean states. As discussed earlier, shallower mean D23 can be found during both winter-early spring and summer-fall seasons (Figs. 4c, 7a), and the summer-fall upwelling is much stronger than the winter-early spring upwelling with a mean D23 of $84 \mathrm{~m}$ during August-October and $100 \mathrm{~m}$ during February-April.

Overall, the interannual D23A in HYCOM EXP presents a similar magnitude and propagation feature to that of HYCOM MR, and remotely forced Kelvin waves are the major cause for interannual variability of D23 in the EIO (cf. Fig. 6b and Fig. 6c). Local forcing, however, also has significant contribution to D23 variability during some years (Fig. 6d). To further quantify the above arguments, we obtain the time series of D23 in the SR from HYCOM MR and EXP (Fig. 7b). The STD of $\mathrm{D} 23 \mathrm{~A}$ is $15.3 \mathrm{~m}$ for the MR, $11.0 \mathrm{~m}$ for EXP, and $5.5 \mathrm{~m}$ for MR - EXP during 2001-11, with remotely forced D23A STD, STD(EXP)/STD(MR), being 72\% and locally forced D23A, STD(MR - EXP)/STD(MR), being 36\%. Note that the contributions of local and remote forcing effects do not add up linearly to 1 because of the nonlinearity of STD calculation formula. The correlation coefficient between MR and EXP (MR - EXP) D23A is $0.96(0.84)$. Note that remote forcing always intensifies local forcing in causing D23A, suggesting that zonal wind along the equator and alongshore wind along the coasts of Sumatra and Java have consistent signs in generating D23A and that equatorial and coastal Kelvin waves propagate fast. Surface winds that induce equatorial EIO upwelling possess basin-scale structures, which are often associated with interannual climate variability modes, such as IOD and ENSO.

Compared to D23A, the propagation of interannual SSTA is less apparent (Fig. 6e), and SSTA results mainly from local forcing (Figs. 6e-g). Although the correlation coefficient between MR and EXP SSTA reaches 0.73 , 

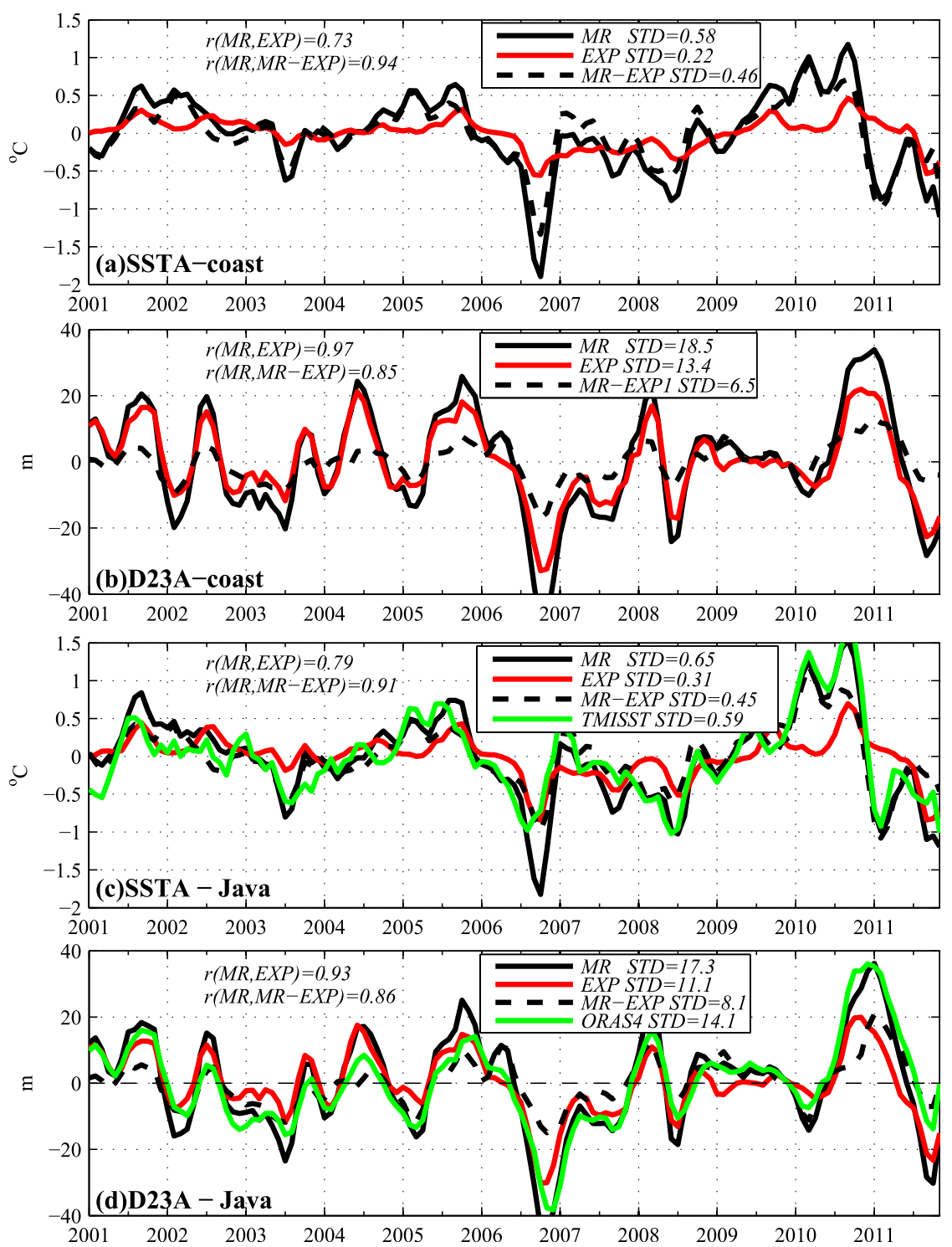

FIG. 8. (a) Interannual SSTA and (b) interannual D23A along the coast of Sumatra and Java labeled by the purple line from B to D in Fig. 2a from HYCOM MR, EXP, and their difference MR - EXP. (c),(d) As in (a) and (b), but for the Java coastal area $\left(10^{\circ} \mathrm{S}-\mathrm{Java}\right.$ coast, $106^{\circ}-$ $114^{\circ} \mathrm{E}$; the small box south of Java in Fig. 2b). SSTA from TMISST and D23A from ORAS4 are also plotted as green lines in (c) and (d), respectively.

the STD of EXP is only $0.21^{\circ} \mathrm{C}$, which is much smaller than the $0.53^{\circ} \mathrm{C}$ STD in the MR and the $0.41^{\circ} \mathrm{C}$ STD in the MR - EXP (Fig. 7d). Note that while the mean seasonal cycle of D23 shoals twice per year, and hence exhibits significant semiannual variability in the EIO (Fig. 7a), SST shows a typical annual cycle with only one minimum occurring during August-October when the mean thermocline is the shallowest ( $84 \mathrm{~m}$ averaged for August-October; Fig. 7c).

To examine the sensitivity of results to the selection of regions (e.g., coastal area vs interior basin), we analyzed D23A and SSTA along the coast of Sumatra and Java labeled by the purple line from B to D in Fig. 2a. Both
SSTA and D23A show stronger interannual variability than those averaged in the SR, with STD values being $9 \%$ and $21 \%$ larger than the SR, respectively. Similar to the $\mathrm{SR}$, interannual D23A is still dominated by Kelvin waves induced by the remote equatorial forcing, whereas interannual SSTA is primarily contributed from local forcing (Figs. 8a,b). We have also examined D23A and SSTA only in the Java coastal area, which is farther away from the equator $\left(10^{\circ} \mathrm{S}-\mathrm{Java}\right.$ coast, $106^{\circ}-114^{\circ} \mathrm{E}$; the small box south of Java in Fig. 2b). In this region, local zonal wind stress variations (Fig. 1) are strong, which contributes substantially to interannual variability of D23. The higher 
correlation between D23A and SSTA in this region (Fig. 2c) suggests that upwelling is a dominant cause for the SSTA, and remote forcing from the equator can also affect D23A and thus SSTA. Thus, both remote and local forcing effects are important to SSTA and D23A in this area. The ratios of STD(EXP)/STD(MR) and STD(MR - EXP)/ STD(MR) for SSTA are $48 \%$ and $63 \%$, respectively, and the corresponding ratios for D23A are $64 \%$ and $47 \%$ (Figs. 8c,d).

\section{3) Processes controlling interannual SSTA}

During the summer-fall season, for all strong upwelling events that occurred in the EIO, cold SSTA corresponds to shallower D23 there, such as 2003, 2006, 2007, 2008, and 2011 (cf. Fig. 6b and Fig. 6e; Fig. 7d, thick and thin black curves). For the weak upwelling (or anomalous downwelling) events that occurred during summer-fall seasons of 2001, 2005, and 2010, the positive SSTA corresponds to positive D23A. These results suggest that during the EIO seasonal upwelling season when the mean thermocline is relatively shallow (Fig. 7a), anomalous strong and weak upwelling can have a significant impact on interannual SSTA. In addition to the high seasonal correction between SST and D23 during September-October (Annamalai et al. 2003), if only the summer-fall interannual events are considered, the correlation between interannual SSTA and D23A is also high with a value of 0.81 from May to October during our period of interest.

By contrast, during winter-spring (NovemberApril) when the mean thermocline is relatively thick, SSTA is not apparently related to D23A. For instance, the negative SSTAs in winter-spring 2008 and 2011 correspond to deepened D23, and positive SSTAs during winter-spring 2002, 2005, and 2010 correspond to shoaled D23. In some years large D23As are not accompanied by significant SSTAs (e.g., winter 2003 and 2004). If only the winter-spring events are considered, there is negative correlation between SSTA and $\mathrm{D} 23 \mathrm{~A}$ with correlation coefficient being -0.38 from November to April. The weak SSTA-D23A correlation (0.26) for the entire 2001-11 period results from the positive correlation during summer-fall season and negative correlation during winter-spring. These results suggest that different processes determine the EIO interannual SSTA during summerfall and winter-spring.

Variability of SST in the surface mixed layer is affected by surface heat fluxes, horizontal advection, and subsurface processes-upwelling and entrainment. While upwelling cooling is through a dynamical process (vertical temperature advection induced by surface
Ekman divergence), entrainment cooling is through mixed layer physics. Statistical analysis shows that the correlation coefficient between SSTA and net surface heat flux anomaly (positive heat flux means heat gain for ocean) in the SR is -0.29 during $2001-11$ and reaches as large as -0.51 when SSTA leads by 1 month when all months are considered (Fig. 9a). When only the summer-fall (May-October) season is considered, the correlation coefficient between the SSTA changing rate $\partial \mathrm{SSTA} / \partial t$ and surface heat flux anomaly is -0.57 when SSTA changing rate leads by 1 month. By contrast, during winter-spring (November-April) $\partial \mathrm{SSTA} / \partial t$ and surface heat flux anomaly are positively correlated, with a correlation coefficient being 0.67 with zero lag. These results suggest that surface heat fluxes are not the major cause for SSTA during the summer-fall upwelling season; rather, feedback of SSTA to the atmosphere through turbulent heat fluxes affects interannual variability of net surface heat flux. When SSTA is negative (positive), the ocean loses less (more) heat to the atmosphere, and thus the net heat flux into the ocean is increased (decreased). During winter-spring, however, surface heat fluxes are important in causing interannual SSTA.

Consistent with the empirical analysis above, the outof-phase relationships between SSTA and surface heat flux anomaly are clearly seen for the strong summerfall upwelling events (e.g., 2003, 2006, 2007, 2008, and 2011) in both the SR and Java coastal area (Fig. 9a). For these events, the SSTAs correlate well with D23As, and remote forcing from the equator has a comparable contribution as local forcing to the EIO SSTA (Figs. 6b,e and 7d; compare the red and dashed black curves of Fig. 7d). Upwelling induced by both remote wind from the equator and local wind in the EIO causes SSTA, which feeds back to the atmosphere to affect the surface turbulent and thus net heat fluxes. This may contribute to the lag of net surface heat flux to SSTA. To further demonstrate this point, Figs. 10a-e show composite analysis of the five upwelling events. During the peak of the upwelling, thermocline shoals, mixed layer thins, and cold SSTA attain their maximum magnitude (Figs. 10b,d,a). Surface heat flux, however, increases as SST decreases, and it obtains the maximum amplitude 1 month after the cold SSTA peak (Fig. 10c). Given that the MLD thins along with the shoaling D23, upwellingrather than entrainment-is the dominant process that causes the cold SSTA. We also examined the weak upwelling (anomalous downwelling) events during summerfall of 2001, 2005, and 2010 and found similar processes dominating the warmer SSTA (Fig. S3).

Different from the summer-fall season, winter-spring cold SSTA (2008 and 2011) and warm SSTA $(2002,2005$ 

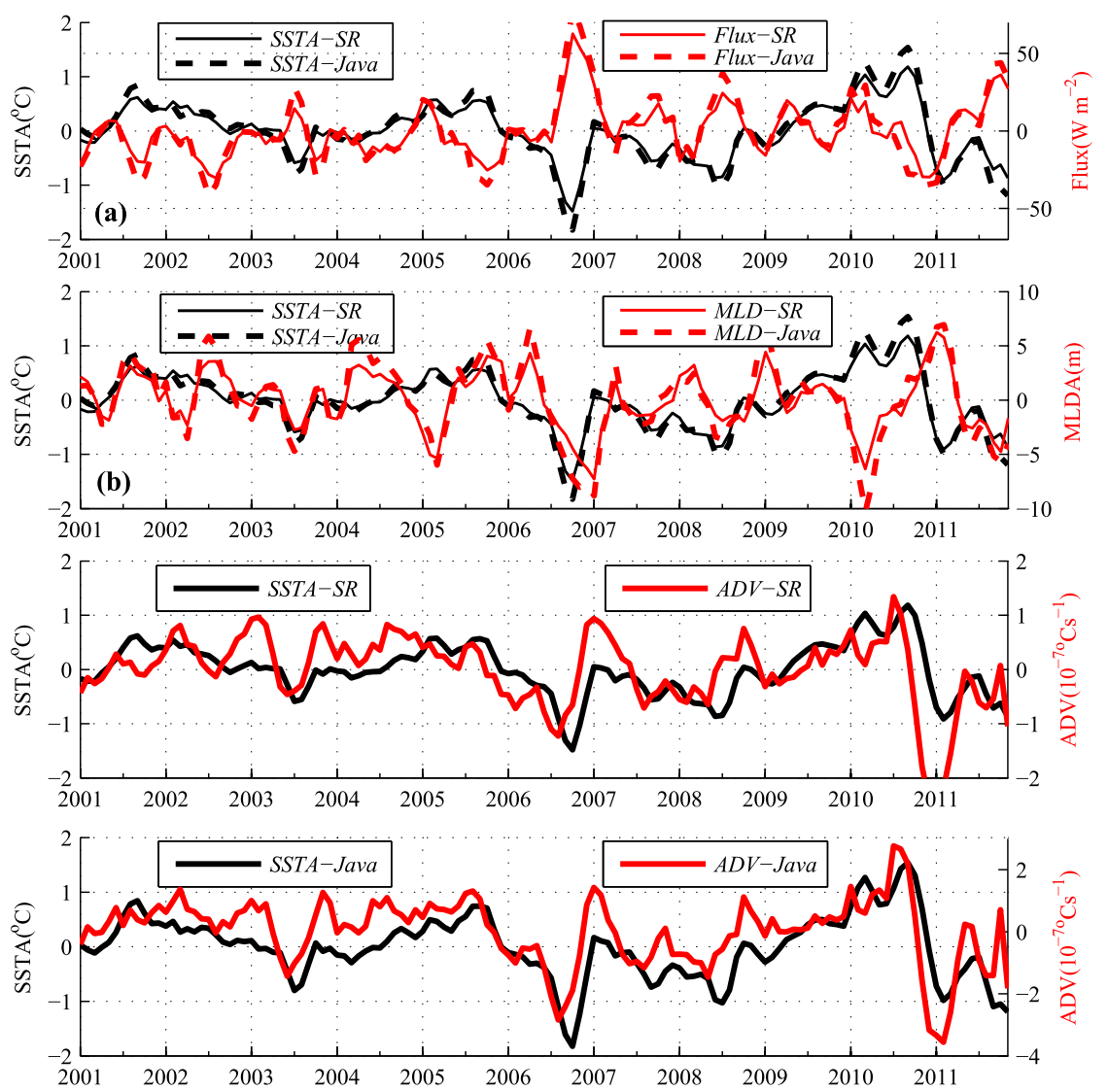

FIG. 9. (a) Interannual SSTA and net surface heat flux anomaly from HYCOM MR averaged in the EIO SR (solid curve) and in the Java coastal area (dashed curve). See Fig. 2 for the EIO SR and Java coastal area. (b) As in (a), but for interannual SSTA and MLD anomaly. (c) As in (a), but for interannual SSTA and advection (ADV) anomaly from the MR EIO SR. (d) As in (c), but for the Java coastal area.

and 2010) events show an out-of-phase relationship with D23A (Fig. 7d) but in-phase relationship with net surface heat flux anomalies (Fig. 9a). Surface heat flux and MLD anomalies are highly correlated, with a correlation coefficient of -0.68 for all months during our period of interest. In addition to direct heating (cooling), the increased (decreased) surface heat flux stabilizes (destabilizes) stratification and thus thins (thickens) the mixed layer, reducing (increasing) the entrainment cooling and thus warming (cooling) SST. These processes can be more clearly seen in the composite of the two cold SSTA events that occur during the winterspring season (Figs. 10f-j). Because of the out-of-phase relationship between SSTA and D23A (Figs. 10f,g), upwelling is not the cause for the cold SSTA. The reduced surface heat flux (Fig. 10h) and enhanced entrainment (deepened MLD in Fig. 10i) cooling are the causes for the cold SSTA. Similarly, the positive SSTA during the three winter-spring warm events is caused by the large surface heat flux and weak entrainment cooling anomalies (Fig. S3). Additionally, thinner mixed layer is more sensitive to the surface heat flux and thus enhances the warm SSTA. In contrast to the shallow D23 during summer-fall, the mean winterspring D23 is deep (Fig. 7a). The deep thermocline acts to decouple SSTA from D23A, resulting in the dominance of surface heat flux and entrainment cooling in causing the SSTA.

To estimate the effect of heat advection on the mixed layer heat budget of the SR, we calculate the mixed layer horizontal advection term (ADV) $-\langle U\rangle \cdot \nabla\langle T\rangle$, where $\langle T\rangle$ and $\langle U\rangle$ are the vertical average of temperature and horizontal velocity over the mixed layer, and $\nabla=(\partial / \partial x$, $\partial / \partial y)$ is the horizontal gradient. Figure 9c shows interannual variability of ADV in the SR, which is significantly correlated with $\partial \mathrm{SSTA} / \partial t$ (SSTA) with a correlation coefficient of 0.57 (0.44) for all months. Composite analysis suggests that advection reaches its minimum when SSTA and D23A reach their minima for the strong summer-fall upwelling events (Fig. 10e) and 

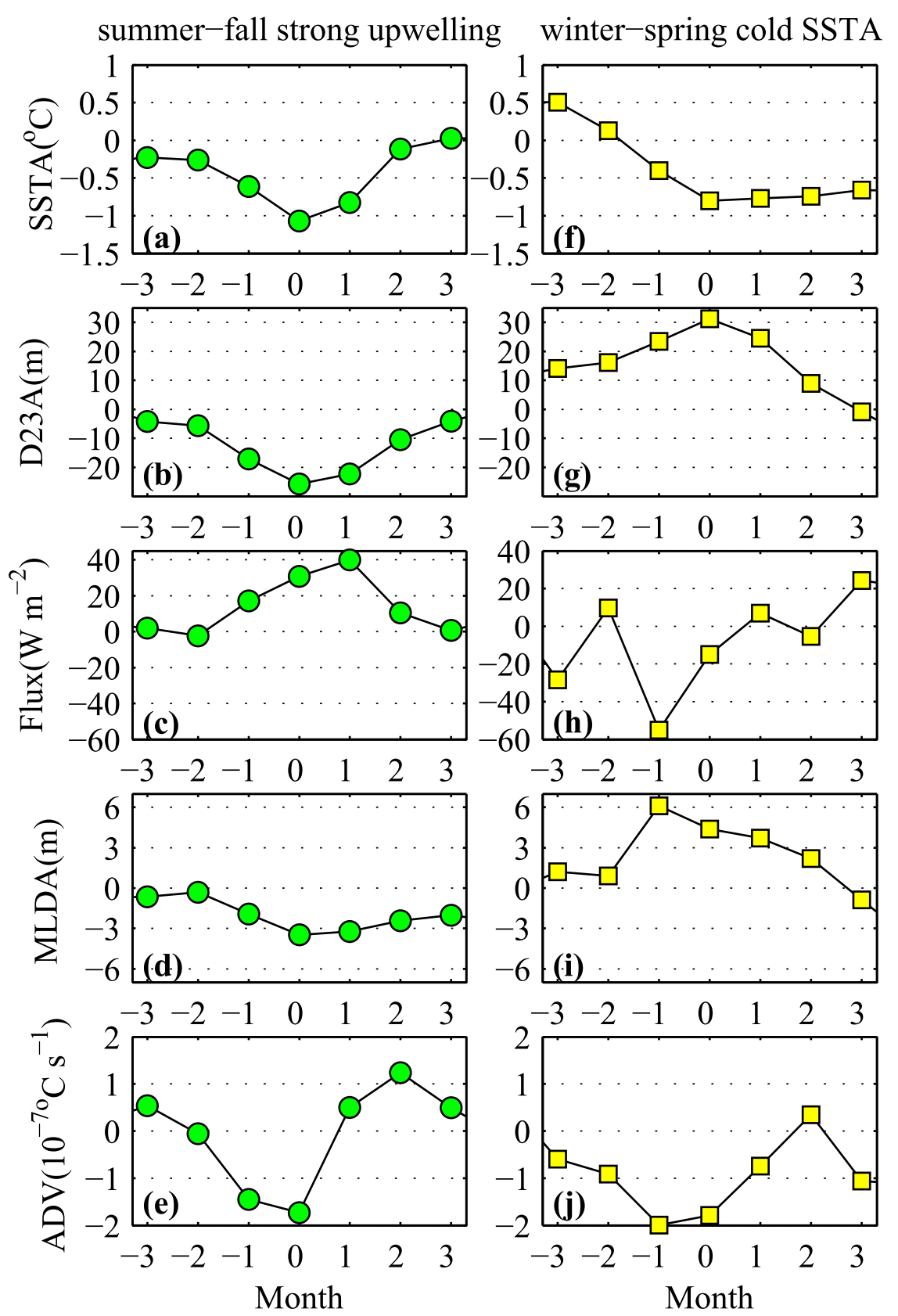

FIG. 10. Composite of (a) SSTA, (b) D23A, (c) net surface heat flux anomaly, (d) MLD anomaly, and (e) ADV anomaly for the strong summer-fall upwelling events in 2003, 2006, 2007, 2008, and 2011. (f)-(j) As in (a)-(e), but for winter-spring cold SSTA events in 2008 and 2011.

therefore contribute to the cold SSTA. Temperature ADV also contributes to winter-spring cold events (Fig. 10j), summer-fall weak upwelling events, and winter-spring warm SSTA events (figure not shown). Our analyses suggest that the relationships among surface heat flux, MLD, ADV, and SSTA in Java coastal area are similar to those of the SR (Fig. 9).
To further quantify the processes controlling interannual variability of the EIO SST, heat budget analysis is performed. Considering that the heat budget can be different between open ocean and coastal area (Halkides and Lee 2009), we calculate the heat budget not only for the SR but also for the Sumatra $\left(-6.75^{\circ} \mathrm{S}\right.$, $110^{\circ}-116^{\circ} \mathrm{E}$; Fig. $\left.2 \mathrm{~b}\right)$ and Java coastal areas. The heat 
MR

(a) summer-fall strong upwelling (b) winter-spring cold SSTA
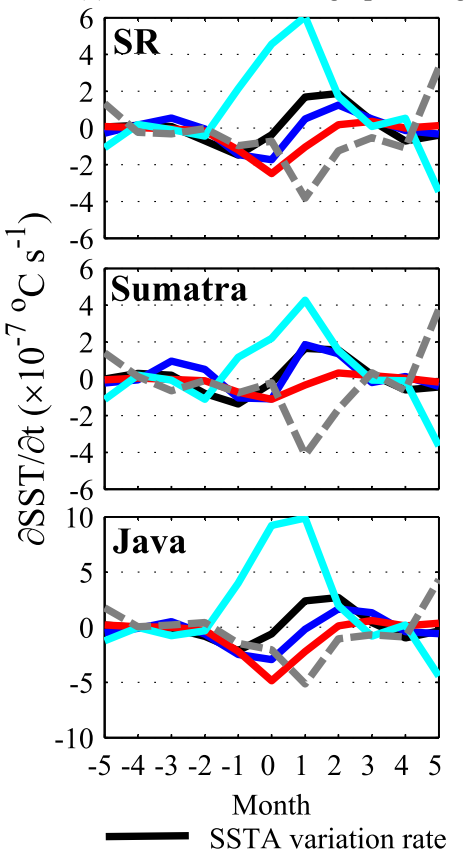

MR
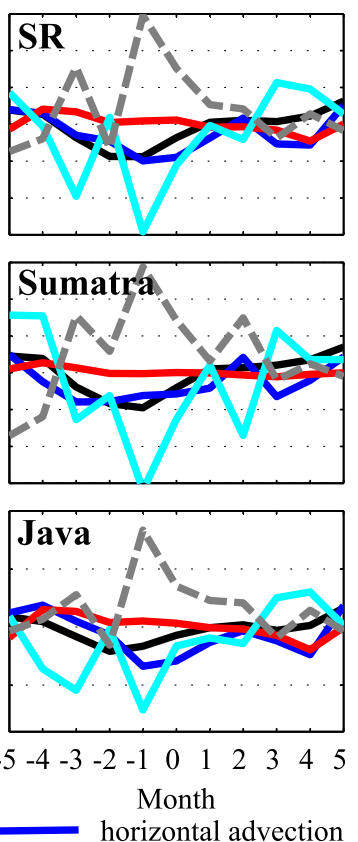

EXP

(c) summer-fall strong upwelling (d) winter-spring cold SSTA
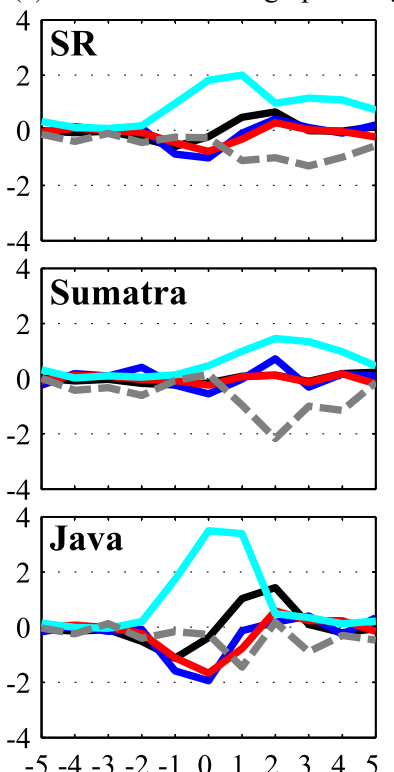

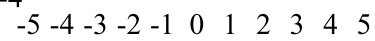
Month subsurface process
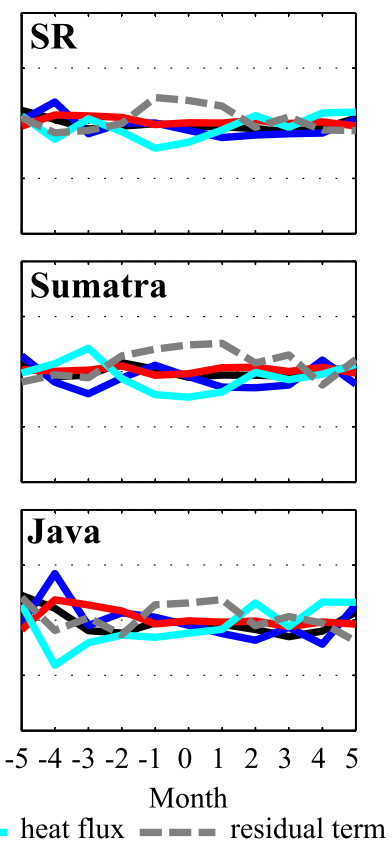

FIG. 11. Heat budget analysis based on the MR solution for (a) summer-fall strong upwelling events and (b) winter-spring cold SSTA events in the SR, Sumatra, and Java coastal areas. (c)-(d) As in (a)-(b), but based on the EXP solution.

budget equation in the surface mixed layer can be expressed by

$\frac{\partial\langle T\rangle}{\partial t}=-\langle U\rangle \cdot \nabla\langle T\rangle-\frac{1}{h}\left[\langle T\rangle-T_{d}\right] w_{e}(-h)+\frac{Q_{\text {net }}}{\rho_{0} C_{p} h}+R$,

where $T_{d}$ is the temperature of water that is entrained into the mixed layer, taken to be the temperature at $5 \mathrm{~m}$ below MLD (Du et al. 2005). The term $Q_{\text {net }}$ is the net surface heat flux, $h$ is the MLD, and the residual term $R$ represents the sum of all unresolved physical processes and the accumulation of errors from the other terms. The anomalous mixed layer temperature can be equivalent to SSTA. Entrainment rate is denoted by $w_{e}(-h)$, which satisfies

$$
w_{e}(-h)=w(-h)+\partial_{t} h+U(-h) \nabla h .
$$

Here, vertical velocity $w(-h)$ at the mixed layer base is the upwelling rate and is estimated from the continuity equation.

Based on the MR output, the heat budget for the summer-fall strong upwelling events discussed above are shown in Fig. 11a. The ADV [the first term on the right-hand side of Eq. (1); blue line in Fig. 11a] and subsurface processes [the second term on the right-hand side of Eq. (1); red line in Fig. 11a] contribute significantly to the SSTA cooling with some differences among the three regions. Subsurface processes play a more important role than ADV in the SR and Java coastal area but contribute approximately equally as ADV near the Sumatra coast. Upwelling thins the mixed layer and thus increases SST cooling. Meanwhile, entrainment tends to thicken the mixed layer by entraining colder thermocline water into the surface mixed layer. Therefore, in a mixed layer heat budget model, entrainment cooling and upwelling cooling cannot be completely separated. Considering that MLD thins during the summer-fall strong upwelling events shown in Fig. 10d, the main subsurface process that induces the cold SSTA is attributed to upwelling but not entrainment. Similar processes determine summer-fall weak upwelling events (figure not shown). As opposed to summer-fall, the winter-spring cold SSTA events are mainly dominated by heat flux and ADV and are less affected by subsurface processes (Fig. 11b). The situation of winterspring warm SSTA events shows similar processes (figure not shown). These budget analyses are consistent with the results from our earlier discussions (Figs. 9, 10). Note, however, that the residual term of the budget is as large as, and sometimes even larger than, the other terms (Fig. 11, gray dashed lines), suggesting large uncertainties in the budget calculation. 


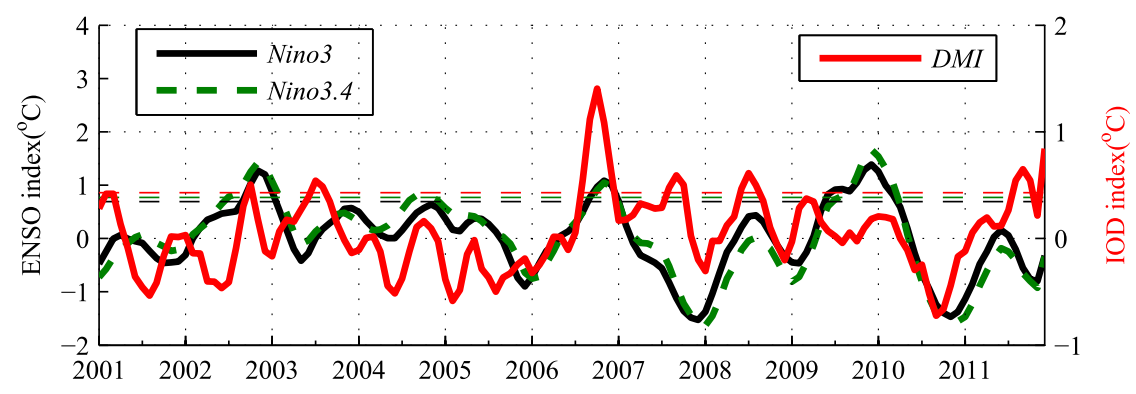

FIG. 12. Niño-3 index, Niño-3.4 index, and DMI index from 2001 to 2011. The three horizontal black, green, and red dashed lines show +1 STD of Niño-3 index, Niño-3.4 index, and DMI index calculated during the same period, respectively.

Heat budget analysis is also applied to EXP output, which excludes local forcing by wind and heat flux that affect entrainment rate. The amplitudes of SSTA become significantly weaker (Figs. 11c,d), further confirming that local forcing plays a large role in determining SSTA variation. In addition to ADV, subsurface processes induced by remote forcing also contribute significantly to SSTA during summer-fall (Fig. 11c), which proves that upwelling contributes substantiality to SSTA in this season. As only monthly climatological forcing is retained in the SR in EXP, heat flux variations during summer-fall are due to feedback of SSTA to the surface turbulent heat fluxes. By contrast, heat fluxes present weak variations during winter-spring (Fig. 11d), suggesting that remote forcing contributes less to the SSTAs due to the deep thermocline and thus has less feedback to surface heat fluxes.

\section{Summary and discussion}

The equatorial EIO upwelling, which occurs in the Indian Ocean side of the Indo-Pacific warm pool (Fig. 1), can not only induce coastal ecosystem changes but also potentially affect regional and global climate by altering the warm pool SST. Combining observational analyses with model experiments using HYCOM, this study systematically quantifies the contributions from the local forcing within the EIO region (SR; Fig. 2) and remote forcing outside the region, primarily from the equator, to interannual variability of the equatorial EIO upwelling during 2001-11. This quantified assessment of remote versus local forcing, together with detailed budget analysis and process discussion for the equatorial EIO upwelling events over an 11-yr period, has not been done by previous studies. In addition to examining SSTA as in previous studies, we also examine the interannual variability of thermocline depth (D23; section 2a), which has a strong influence on interannual SSTA in the EIO during summer-fall season. The HYCOM realistically simulates the interannual variability of SST, $\mathrm{SSH}$, thermocline depth, and MLD (Fig. 3) and thus serves the purpose of this study.

On seasonal time scales, the EIO D23 has a significant semiannual variability, shoaling during boreal winterearly spring from January to March and during summerfall from June to September and deepening for the rest of the year. The D23 reaches its shallowest depth during summer-fall season, with corresponding low SST and high Chl- $a$ concentration (Figs. 2, 4). The shoaling of D23 during winter-spring, however, has no corresponding SST and Chl- $a$ signals because local winds are downwelling favorable (Figs. 1, 4), which counteract the upwelling induced by the remote equatorial winds.

On interannual time scales, the $\mathrm{D} 23$ signals propagate eastward along the equator as equatorial Kelvin waves and propagate southeastward along the coasts of Sumatra and Java as coastal Kelvin waves, affecting the D23A in the EIO (Fig. 6). The EIO interannual D23A is primarily controlled by remote forcing from the equatorial Indian Ocean (Figs. 5, 6), with a STD of $15.3 \mathrm{~m}$ in HYCOM MR; $11.0 \mathrm{~m}$ in HYCOM EXP, which estimates the remote forcing; but only $5.5 \mathrm{~m}$ in MR - EXP, which measures local forcing (Fig. 7b). Different from D23A, interannual variability of EIO SST results mainly from local forcing, with a STD of $0.53^{\circ} \mathrm{C}$ in the MR, $0.41^{\circ} \mathrm{C}$ in MR - EXP related to local forcing, but only $0.21^{\circ} \mathrm{C}$ in EXP related to remote forcing (Fig. 7d). During the summer-fall season when the mean D23 is shallow (Fig. 7a), D23A is in phase with SSTA, and anomalous upwelling dominates the SSTA. By contrast, during winter-spring when the mean D23 is deep, strong SSTA is often out of phase with D23A, and the SSTA is primarily induced by surface heat flux (Figs. 9, 10). Advection has a significant contribution in all cases. Near the Java coast, both remote and local forcing are important for SSTA and D23A (Fig. 8), with STD (EXP)/STD(MR) and STD(MR - EXP)/STD(MR) for SSTA being $48 \%$ and $63 \%$, respectively, and the corresponding ratios for D23A being $64 \%$ and $47 \%$, even 

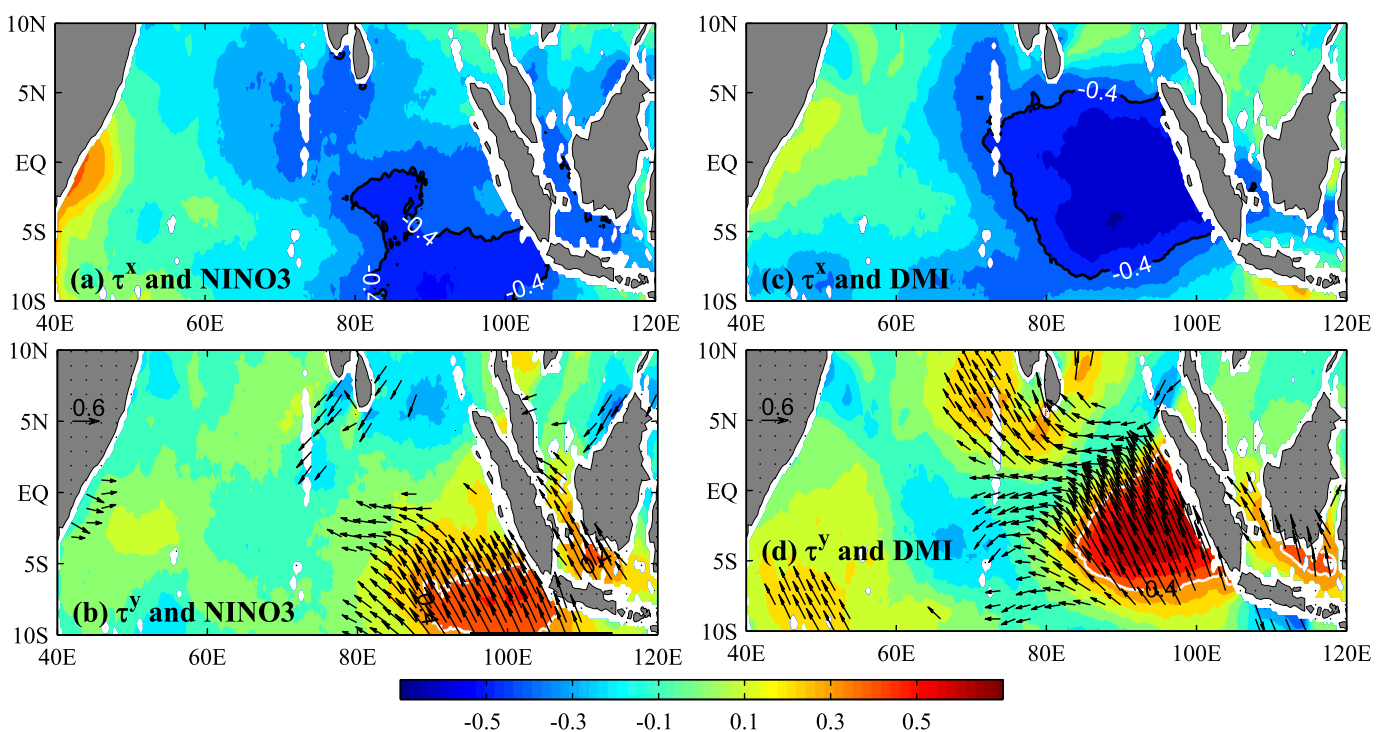

FIG. 13. (a) Correlation coefficients between interannual anomaly of $\tau^{x}$ at each grid point and Niño-3 index for the 2001-11 period. (b) As in (a), but for $\tau^{y}$ and Niño-3 index. (c)-(d) As in (a) and (b), but for wind stress and DMI. The thick line contour in (a) and (c) and in (b) and (d) represents -0.4 and 0.4 contours, respectively. Partial correlations of wind stress with Niño-3 index and DMI index are plotted in (b) and (d) by vectors. Only regions with a correlation coefficient over 0.3 are plotted.

though remote (local) forcing is somewhat more important for D23A (SSTA).

Heat budget analysis further verifies our above arguments on the importance of subsurface processes (entrainment and upwelling) during summer-fall and surface heat fluxes during winter-spring in causing the upwelling events in the SR, near Sumatra coast and Java coast (Fig. 11). Advection has significant contributions to all cases. These results are consistent with the budget analysis of Murtugudde et al. (2000) for 1997 and Halkides and Lee (2009) for 1994, 1997, and 2006 upwelling events over the EIO and near-coastal region. While both our analysis and Du et al. (2008) suggest the importance of subsurface processes in determining interannual SSTA in the Sumatra and Java regions, our results also show the importance of advection, differing from results of $\mathrm{Du}$ et al. (2008) that advection only cools SSTA in the Sumatra region. Note that it is very difficult to close the budget using offline model output or observational data. The residual term (dashed gray lines in Fig. 11) is often as large as, and sometimes larger than, the other process terms, suggesting that the results of the heat budget analysis contain large uncertainties. That is the reason for us to fully examine different processes (Figs. 9, 10) before we perform the heat budget analysis. The large uncertainties mainly originate from heat flux items at the SSTA warming stage during summer-fall upwelling events (Fig. 11a) and at the SSTA cooling stage during winter-spring cold SSTA events (Fig. 11b), when larger heat flux amplitudes exist. This suggests that heat budget analysis may overestimate contributions of heat flux to SSTA variation.

Susanto et al. (2001) showed that the correlation between the thermocline temperature anomaly along the Sumatra-Java coasts and the Southern Oscillation index (SOI) reached 0.6, suggesting the importance of ENSO in affecting the equatorial EIO upwelling. Note that ENSO can affect equatorial EIO upwelling by changing the surface wind via the atmospheric bridge and through oceanic connection via the Indonesian Throughflow (ITF), with El Niño events favoring the equatorial EIO upwelling. While El Niño events occurred in 2002, 2006, and 2009 during the 2001-2011 period (Fig. 12), no strong upwelling occurred in the EIO in 2002 and 2009, and the 2006 El Niño cooccurred with the IOD. Evident upwelling events occurred in summer-fall 2003, 2006, 2007, 2008, and 2011 (Fig. 9), and they all correspond to larger DMI. While the Niño-3 index has a higher correlation with D23A in the SR with a correlation coefficient of -0.38 during 2001-2011, its correlation with SSTA in the EIO is only 0.08 . As shown above, interannual variability of D23 is dominated by remote equatorial forcing, with part contribution from local forcing. Figure 13 shows correlation map between surface wind stress and the Niño-3 index (DMI) for all months from 2001 to 2011. Evidently, zonal wind stress in the eastern equatorial Indian Ocean is more correlated with the DMI index and less correlated with Niño-3 index (Figs. 13a,c). Meridional winds in the EIO are also mainly associated with DMI 
(Figs. 13b,d). We have also calculated partial correlation coefficients between wind stress and Niño-3 index (DMI) as in $\mathrm{Yu}$ et al.(2005; vectors in Figs. 13b,d), and they further suggest that IOD is more important than ENSO in affecting the Indian Ocean winds and thus equatorial EIO upwelling. Conclusions do not change if only summer-fall data are used (Fig. S4). The correlation coefficient between SSTA (D23A) and DMI reaches -0.66 $(-0.47)$. These results suggest that the equatorial EIO upwelling has an evidently stronger association with the IOD than with ENSO, which agrees with the view of Webster et al. (1999).

Note that both HYCOM MR and EXP do not have an active ITF (only the $T$ and $S$ fields are relaxed to their climatological fields). However, the simulated SSTA, SSHA, and D23A in the SR and the Java coastal area from HYCOM MR agree well with the observations (Fig. 3). One evident model/data discrepancy occurs in 2006 for the Java Sea (Fig. 8c), when HYCOM SSTA is much colder than the observation. This simulated colder SSTA cannot be explained by the lack of ITF in HYCOM, since an active ITF would further cool the Java Sea during the 2006 El Niño. These results indicate that significant ENSO influence on the equatorial EIO upwelling might be through the atmospheric bridge rather than through the ITF variability. Further quantitative examination, however, is required in order to prove this assertion.

Acknowledgments. Gengxin Chen is supported by the "Strategic Priority Research Program" of the Chinese Academy of Sciences (Grants XDA11010302 and XDA11010103), National Natural Science Foundation of China (Grants 41476011, 41521005, 41476012, and 41206008), and Pearl River S\&T Nova Program of Guangzhou (2013J2200087). Weiqing Han and Yuanlong $\mathrm{Li}$ are supported by NSF Climate and Large-Scale Dynamics Award 1446480 and NOAA Award NA11OAR4310100. Dongxiao Wang is supported by the CAS/SAFEA International Partnership Program for Creative Research Teams and the External Cooperation Program of BIC, CAS (Grant GJHZ201319).

\section{REFERENCES}

Aiken, J., G. F. Moore, C. C. Trees, S. B. Hooker, and D. K. Clark, 1995: The SeaWiFS CZCS-type pigment algorithm. NASA Tech. Memo. 104566, SeaWiFS Tech. Rep. Series, Vol. 29, NASA Goddard Space Flight Center, 34 pp.

Annamalai, H., R. Murtugudde, J. Potemra, S. P. Xie, P. Liu, and B. Wang, 2003: Coupled dynamics over the Indian Ocean: Spring initiation of the zonal mode. Deep-Sea Res. II, 50, 23052330, doi:10.1016/s0967-0645(03)00058-4.
Atlas, R., J. Ardizzone, and R. N. Hoffman, 2008: Application of satellite surface wind data to ocean wind analysis. Remote Sensing System Engineering, P. E. Ardanuy and J. J. Puschell, Eds., International Society for Optical Engineering (SPIE Proceedings, Vol. 7087), 70870B, doi:10.1117/ 12.795371 .

Balmaseda, M. A., K. Mogensen, and A. T. Weaver, 2013: Evaluation of the ECMWF ocean reanalysis system ORAS4. Quart. J. Roy. Meteor. Soc., 139, 1132-1161, doi:10.1002/qj.2063.

Baumgart, A., T. Jennerjahn, M. Mohtadi, and D. Hebbeln, 2010: Distribution and burial of organic carbon in sediments from the Indian Ocean upwelling region off Java and Sumatra, Indonesia. Deep-Sea Res. I, 57, 458-467, doi:10.1016/ j.dsr.2009.12.002.

Bleck, R., 2002: An oceanic general circulation model framed in hybrid isopycnic-Cartesian coordinates. Ocean Modell., 4, 5588, doi:10.1016/S1463-5003(01)00012-9.

Chen, G., W. Han, Y. Li, D. Wang, and M. J. McPhaden, 2015a: Seasonal-to-interannual time scale dynamics of the Equatorial Undercurrent in the Indian Ocean. J. Phys. Oceanogr., 45, 1532-1553, doi:10.1175/JPO-D-14-0225.1.

,,,$----\longrightarrow$, and T. Shinoda, 2015b: Intraseasonal variability of upwelling in the equatorial eastern Indian Ocean. J. Geophys. Res. Oceans, 120, 7598-7615, doi:10.1002/ $2015 \mathrm{JC} 011223$.

Clarke, A. J., and X. Liu, 1993: Observations and dynamics of semiannual and annual sea levels near the eastern equatorial Indian Ocean boundary. J. Phys. Oceanogr., 23, 386-399, doi:10.1175/1520-0485(1993)023<0386:OADOSA > 2.0.CO;2.

Dee, D. P., and Coauthors, 2011: The ERA-Interim reanalysis: Configuration and performance of the data assimilation system. Quart. J. Roy. Meteor. Soc., 137, 553-597, doi:10.1002/qj.828.

Du, Y., T. Qu, G. Meyers, Y. Masumoto, and H. Sasaki, 2005: Seasonal heat budget in the mixed layer of the southeastern tropical Indian Ocean in a high-resolution ocean general circulation model. J. Geophys. Res., 110, C04012, doi:10.1029/ 2004JC002845.

,-- , and,- 2008 : Interannual variability of sea surface temperature off Java and Sumatra in a global GCM. J. Climate, 21, 2451-2465, doi:10.1175/2007JCLI1753.1.

Ducet, N., P. Le Traon, and G. Reverdin, 2000: Global highresolution mapping of ocean circulation from TOPEX/Poseidon and ERS-1 and-2. J. Geophys. Res., 105, 19477-19498, doi:10.1029/ 2000JC900063.

Girishkumar, M. S., M. Ravichandran, and W. Han, 2013: Observed intraseasonal thermocline variability in the Bay of Bengal. J. Geophys. Res. Oceans, 118, 3336-3349, doi:10.1002/ jgrc.20245.

Grumet, N. S., N. J. Abram, J. W. Beck, R. B. Dunbar, M. K. Gagan, T. P. Guilderson, W. S. Hantoro, and B. W. Suwargadi, 2004: Coral radiocarbon records of Indian Ocean water mass mixing and wind-induced upwelling along the coast of Sumatra, Indonesia. J. Geophys. Res., 109, C05003, doi:10.1029/ 2003JC002087.

Halkides, D. J., and T. Lee, 2009: Mechanisms controlling seasonalto-interannual mixed layer temperature variability in the southeastern tropical Indian Ocean. J. Geophys. Res., 114, C02012, doi:10.1029/2008JC004949.

Han, W. Q., P. J. Webster, J. L. Lin, W. T. Liu, R. Fu, D. L. Yuan, and A. X. Hu, 2008: Dynamics of intraseasonal sea level and thermocline variability in the equatorial Atlantic during 2002-03. J. Phys. Oceanogr., 38, 945-967, doi:10.1175/ 2008JPO3854.1. 
_ J. P. McCreary, Y. Masumoto, J. Vialard, and B. Duncan, 2011 Basin resonances in the equatorial Indian Ocean. J. Phys. Oceanogr., 41, 1252-1270, doi:10.1175/2011JPO4591.1.

Iskandar, I., S. Rao, and T. Tozuka, 2009: Chlorophyll- $a$ bloom along the southern coasts of Java and Sumatra during 2006. Int. J. Remote Sens., 30, 663-671, doi:10.1080/01431160802372309.

Kara, A. B., H. E. Hurlburt, and A. J. Wallcraft, 2005: Stabilitydependent exchange coefficients for air-sea fluxes. J. Atmos. Oceanic Technol., 22, 1080-1094, doi:10.1175/JTECH1747.1.

Kim, S. T., J. Y. Yu, and M. M. Lu, 2012: The distinct behaviors of Pacific and Indian Ocean warm pool properties on seasonal and interannual time scales. J. Geophys. Res., 117, D05128, doi:10.1029/2011JD016557.

Kummerow, C., W. Barnes, T. Kozu, J. Shiue, and J. Simpson, 1998: The Tropical Rainfall Measuring Mission (TRMM) sensor package.J. Atmos. Oceanic Technol., 15, 809-817, doi:10.1175/ 1520-0426(1998)015<0809:TTRMMT >2.0.CO;2.

Le Traon, P., F. Nadal, and N. Ducet, 1998: An improved mapping method of multisatellite altimeter data. J. Atmos. Oceanic Technol., 15, 522-534, doi:10.1175/1520-0426(1998)015<0522 AIMMOM $>2.0 . \mathrm{CO} ; 2$.

Li, Y., W. Han, T. Shinoda, C. Wang, R. C. Lien, J. N. Moum, and J. W. Wang, 2013: Effects of the diurnal cycle in solar radiation on the tropical Indian Ocean mixed layer variability during wintertime Madden-Julian oscillations. J. Geophys. Res. Oceans, 118, 4945-4964, doi:10.1002/jgrc.20395.

C. Z. Wang, M. Ravichandran, and J. W. Wang, 2014: Revisiting the wintertime intraseasonal SST variability in the tropical south Indian Ocean: Impact of the ocean interannual variation. J. Phys. Oceanogr., 44, 1886-1907, doi:10.1175/JPO-D-13-0238.1.

_,- , and T. Lee, 2015: Intraseasonal sea surface salinity variability in the equatorial Indo-Pacific Ocean induced by Madden-Julian oscillations. J. Geophys. Res. Oceans, 120, 2233-2258, doi:10.1002/2014JC010647.

Loeb, N. G., K. J. Priestley, D. P. Kratz, E. B. Geier, R. N. Green, B. A. Wielicki, P. O'Rawe Hinton, and S. K. Nolan, 2001: Determination of unfiltered radiances from the clouds and the Earth's Radiant Energy System instrument. J. Appl. Meteor., 40, 822-835, doi:10.1175/1520-0450(2001)040<0822: DOURFT $>2.0 . \mathrm{CO} ; 2$.

McCreary, J. P., S. R. Shetye, and P. K. Kundu, 1986: Thermohaline forcing of eastern boundary currents: With application to the circulation off the west coast of Australia. J. Mar. Res., 44, 71-92, doi:10.1357/002224086788460184.

Murtugudde, R., J. P. McCreary, and A. J. Busalacchi, 2000: Oceanic processes associated with anomalous events in the Indian Ocean with relevance to 1997-1998. J. Geophys. Res., 105, 3295-3306, doi:10.1029/1999JC900294.

Rio, M. H., S. Guinehut, and G. Larnicol, 2011: New CNESCLS09 global mean dynamic topography computed from the combination of GRACE data, altimetry, and in situ measurements. J. Geophys. Res., 116, C07018, doi:10.1029/ $2010 \mathrm{JC} 006505$.

Saji, N. H., B. N. Goswami, P. N. Vinayachandran, and T. Yamagata, 1999: A dipole mode in the tropical Indian Ocean. Nature, 401, 360-363.

Sardeshmukh, P. D., and B. J. Hoskins, 1988: The generation of global rotational flow by steady idealized tropical divergence. J. Atmos. Sci., 45, 1228-1251, doi:10.1175/ 1520-0469(1988)045<1228:TGOGRF>2.0.CO;2.

Schott, F. A., and J. P. McCreary Jr., 2001: The monsoon circulation of the Indian Ocean. Prog. Oceanogr., 51, 1-123, doi:10.1016/S0079-6611(01)00083-0.

Susanto, R. D., and J. Marra, 2005: Effect of the 1997/98 El Niño on chlorophyll $a$ variability along the southern coasts of Java and Sumatra. Oceanography, 18, 124-127, doi:10.5670/ oceanog.2005.13.

— A. L. Gordon, and Q. N. Zheng, 2001: Upwelling along the coasts of Java and Sumatra sand its relation to ENSO. Geophys. Res. Lett., 28, 1599-1602, doi:10.1029/2000GL011844.

Wallcraft, A. J., E. J. Metzger, and S. N. Carroll, 2009: Software design description for the Hybrid Coordinate Ocean Model (HYCOM), version 2.2. Naval Research Laboratory NRL/ MR/7320-09-9166, 149 pp.

Webster, P. J., and R. Lukas, 1992: TOGA COARE: The Coupled Ocean-Atmosphere Response Experiment. Bull. Amer. Meteor. Soc., 73, 1377-1416, doi:10.1175/1520-0477(1992)073<1377: TCTCOR $>2.0 . \mathrm{CO} ; 2$

— A. M. Moore, J. P. Loschnigg, and R. R. Leben, 1999: Coupled ocean-atmosphere dynamics in the Indian Ocean during 1997-98. Nature, 401, 356-360, doi:10.1038/43848.

Wentz, F. J., C. Gentemann, D. Smith, and D. Chelton, 2000: Satellite measurements of sea surface temperature through clouds. Science, 288, 847-850, doi:10.1126/science.288.5467.847.

Wielicki, B. A., B. R. Barkstrom, E. F. Harrison, R. B. Lee, G. L. Smith, and J. E. Cooper, 1996: Clouds and the Earth's Radiant Energy System (CERES): An Earth Observing System experiment. Bull. Amer. Meteor. Soc., 77, 853-868, doi:10.1175/ 1520-0477(1996)077<0853:CATERE > 2.0.CO;2.

Xie, S. P., H. Annamalai, F. A. Schott, and J. P. McCreary, 2002: Structure and mechanisms of south Indian Ocean climate variability. J. Climate, 15, 864-878, doi:10.1175/ 1520-0442(2002)015<0864:SAMOSI >2.0.CO;2.

Yu, W., B. Xiang, L. Liu, and N. Liu, 2005: Understanding the origins of interannual thermocline variations in the tropical Indian Ocean. Geophys. Res. Lett., 32, L24706, doi:10.1029/ 2005 GL024327.

Zelle, H., G. Appeldoorn, G. Burgers, and G. J. van Oldenborgh, 2004: The relationship between sea surface temperature and thermocline depth in the eastern equatorial Pacific. J. Phys. Oceanogr., 34, 643-655, doi:10.1175/2523.1. 